\title{
Estimation of nearshore wave transmission for submerged breakwaters using a data-driven predictive model
}

\author{
Amir Sharif Ahmadian ${ }^{a *}$, Richard R. Simons ${ }^{b}$ \\ Assistant Professor, Department of Civil Engineering, Khajeh Nasir Building, \\ Hormozgan University, Minab Road, Bandar Abbas, Iran \\ Professor, Department of Civil, Environmental and Geomatic Engineering, Chadwick Building,
}

UCL, Gower Street, London WC1E 6BT, UK

\begin{abstract}
The functional design of submerged breakwaters is still developing, particularly with respect to modelling of the nearshore wave field behind the structure. This paper describes a method for predicting the wave transmission coefficients behind submerged breakwaters using machine learning algorithms. An artificial neural network using the radial-basis function approach has been designed and trained using laboratory experimental data expressed in terms of non-dimensional parameters. A wave transmission coefficient calculator is presented, based on the proposed radial-basis function model. Predictions obtained by the radial-basis function model were verified by experimental measurements for a two dimensional breakwater. Comparisons reveal good agreement with the experimental results and encouraging performance from the proposed model. Applying the proposed neural network model for predictions, guidance is given to appropriately calculate wave transmission coefficient behind two dimensional submerged breakwaters. It is concluded that the proposed predictive model offers potential as a design tool to predict wave transmission coefficients behind submerged breakwaters. A step-by-step procedure for practical applications is outlined in a user-friendly form with the intention of providing a simplified tool for preliminary design purposes. Results demonstrate the model's potential to be extended to three dimensional, rough, permeable structures.
\end{abstract}

Keywords: Submerged breakwater; Nearshore wave transmission; Numerical modeling; Artificial neural network; Radial-basis function; Predictive model.

\section{Introduction}

Shoreline erosion has been a concern for mankind throughout history, and today, because of population growth in coastal areas through urbanization and tourism, this concern would be of even greater significance. Detached breakwaters, either emerged or submerged, are a form of coastal defence that are designed and constructed for shoreline protection purposes. Detached breakwaters contribute to dissipation of incident wave energy and provide a calm sheltered area behind the structure. Many researches on detached breakwaters have been performed; see e.g. [1], [2], [3] and [4]. Detached breakwaters are often adopted to protect the shoreline and, among these, submerged breakwaters are increasingly preferred due to the significant dissipation of incident wave energy, lower construction costs, retention of a clear view of the sea and maintenance of high water quality leeside in an environmentallyfriendly way. The latest results on submerged breakwaters seem to be very promising: [5], [6], [7], [8], [9], [10], [11], [12]. However, contribution to the movement and advancement in the new methods and techniques of analysis and design of submerged breakwaters is continuously growing through time. The stimulus of the present paper is to develop an enhanced prediction tool and wave calculator for the transmitted waves behind submerged breakwaters as a step towards the design of more efficient coastal structures. This is basically implemented through the calculation of an averaged coefficient based on the ratio of averaged transmitted wave height behind the structure to incident wave height. This coefficient is used widely to quantify the wave transmitted behind coastal structures such

Corresponding author (A. Sharif Ahmadian).

Telephone number: 00989131763632

E-mail address: a.ahmadian@ucl.ac.uk 
as submerged breakwaters and is known as the wave transmission coefficient $K_{t}$.

The majority of studies on submerged breakwaters are restricted to semi-submerged breakwaters or low-crested structures with a small number considering fully-submerged breakwaters. Calculation of transmitted wave height behind submerged breakwaters has been investigated numerically using data-driven algorithms called Artificial Neural Networks (hereafter ANN). ANN models have been demonstrated to be effective tools in many fields of engineering to solve intricate nonlinear problems where multiple relationships are involved. They have recently been employed widely in the field of coastal engineering ([13], [14], [15], [16], [17], [18], [19], [20], ([21], [22], [23], [24]). Results from tests on wave transmission over submerged breakwaters are very encouraging and have led to several design tools including empirical formulae and neural networks ([25], [26], [27], [28], [29], [12]). In the present study, an ANN model has been designed and trained using the Radial Basis Function (RBF) approach and the results compared with new experimental laboratory data.

RBF networks can be trained much faster than MLP networks. The Gradient Descent method is used in this study to train the RBF network. This is an optimization algorithm used when dealing with an unknown function and for function approximating purposes [30]. It is basically a derivative-based algorithm. Kalman Filtering is an alternative derivative-based algorithm applied in many different practical applications. Genetic Algorithms offer another approach to optimization and are applicable in many engineering problems. They are based on a population-based algorithm. A very slow convergence rate is the main weakness of genetic algorithms [30]. A drawback of Gradient Descent and Kalman Filtering algorithms is related to the local extreme trap when for example the algorithms get trapped in the local minima. Another disadvantage is related to the training process which is sometimes very timeconsuming. A slow convergence rate can be another weakness [30]. The complexity of the RBF network grows significantly with the number of the computational units. Gradient Descent and Kalman Filtering have relatively faster training [30].

The proposed model in this paper is proved to be capable of handling two dimensional wave transmission prediction and could be applied in real practical applications with high accuracy and reliability by engineers and scientists as a more precise and dependable design tool than existing models. The proposed model is a significant advance in that it can be used to predict $\mathrm{K}_{\mathrm{t}}$ consistently behind submerged breakwaters in a wide range of water depths and wave climates whereas existing models in the literature are restricted to calculating wave transmission coefficient in a limited range of input parameters which make them less accurate and reliable with lower usefulness and applicability.

\section{Background}

Various experimental, field or theoretical studies have been undertaken and mathematical and numerical models have been developed to understand and predict the different physical phenomena related to submerged breakwaters. Previous physical models and laboratory experiments, empirical formula, data-driven tools or models, theoretical studies, mathematical or statistical approaches, numerical models and field measurements have been used to investigate the impacts of submerged breakwaters on the wave field leeside. Among these various approaches, empirical formula and data-driven tools are being used widely and are more popular than others. These techniques are applied as simple and easy to use $\mathrm{K}_{\mathrm{t}}$ calculators. This section looks into their historical development and focuses on the previous research into wave transmission behind submerged breakwaters.

Accurate prediction of the coefficient $\mathrm{K}_{\mathrm{t}}$ is an important step in reliable modelling of the morphodynamics of the seabed and shoreline in response to the construction of submerged breakwaters. Most existing approaches employ few physical parameters over a limited range and under some specific test conditions. Full consideration of all the physical parameters involved in the process is not applied in most $\mathrm{K}_{\mathrm{t}}$ calculators for submerged breakwaters, simply because of the very high costs of physical tests or lack of access to the good laboratories. Various calculators have been developed for prediction of the wave transmission coefficient $\left(\mathrm{K}_{\mathrm{t}}\right)$ over and behind the submerged breakwaters ([31]; [32]; [33]; [26]; [34]; [27]; [28]; [29]; [35]; [12]; [36]).

The majority of these calculators are developed from data collected in physical tests and laboratory experiments. Thus, the accuracy and reliability of these tools depend on the quality of the data collected in the laboratories. The first reported physical experiments on the wave transmission behind 2D submerged breakwaters were performed by Stucky and Bonnard [37]. Further studies on 2D structures were reported later by [38], [39], [40], [41], [42], [43], [44], [45] and [46]. 
d'Angremond et al. [32] proposed a more precise expression for transmitted wave height passing over permeable and impermeable submerged breakwaters using data sets from [43]; [44], [47]; [48]; [49] and [50]:

$$
K_{t}=0.4 \frac{h_{s}}{H_{i}}+\left(\frac{B}{H_{i}}\right)^{-0.31} a\left(1-e^{-0.5 \xi}\right)
$$

where $\mathrm{a}=0.64$ and 0.8 for permeable and impermeable breakwaters respectively with limits $0.075<K_{t}<0.80$. In this equation, $h_{s}$ is submergence depth, $H_{i}$ is incident wave height, $B$ is breakwater crest width and $\xi_{0}$ is Iribarren number that can be calculated as follows:

$$
\xi_{o}=\frac{\tan \alpha}{\sqrt{\frac{H_{i}}{L_{o}}}}
$$

in which $L_{o}$ is incident wave length in deep water and $\alpha$ is breakwater seaside slope.

Seabrook and Hall [33] developed a predictive expression for $\mathrm{K}_{\mathrm{t}}$ at submerged rubble mound breakwaters:

$$
K_{t}=1-\left(e^{-0.56\left(\frac{h_{s}}{H_{i}}\right)-1.09\left(\frac{H_{i}}{B}\right)}+0.047\left(\frac{h_{s}}{D_{50}} \cdot \frac{B}{L_{o}}\right)-0.067\left(\frac{h_{s}}{D_{50}} \cdot \frac{H_{i}}{B}\right)\right)
$$

where $\mathrm{D}_{50}$ is diameter of the armor units. The proposed equation by [33] is valid in the following ranges:

$$
\begin{aligned}
& 0 \leq \frac{h_{s}}{D_{50}} \cdot \frac{H_{i}}{B} \leq 2.14 \\
& 0 \leq \frac{h_{s}}{D_{50}} \cdot \frac{B}{L_{o}} \leq 7.08
\end{aligned}
$$

Seabrook and Hall [51] found that the armour size has little effect on wave transmission. Bleck and Oumeraci [52] proposed a modified empirical equation for $\mathrm{K}_{\mathrm{t}}$ using two dimensional experimental data for rectangular impermeable breakwater. The equation, therefore, is only applicable for the rectangular breakwaters and is less reliable for the trapezoidal breakwaters. Calabrese, et al. [53] found that the d'Angremond et al. Equation [32] is more reliable than other previous methods for the prediction of $\mathrm{K}_{\mathrm{t}}$.

The DELOS database (see: [26] and [54]) consists of more than 2300 tests for 2D rubble mound low-crested structures (LCS). van der Meer et al. [25] and [26] improved the 2D empirical formulae for rubble mound lowcrested breakwaters provided by [55] and [32] using the collected data from the DELOS project. The following equations were provided by [25] and [26] for smooth and impermeable low-crested structures:

$$
K_{t}=\left\{\begin{array}{cc}
0.3 \frac{h_{s}}{H_{i}}+0.75\left(1-e^{-0.5 \xi_{o}}\right) & \xi_{o}<3 \\
0.3 \frac{h_{s}}{H_{i}}+\left(\frac{B}{H_{i}}\right)^{0.31} 0.75\left(1-e^{-0.5 \xi_{o}}\right) & \xi_{o} \geq 3
\end{array}\right.
$$

where the values of 0.075 and 0.8 were proposed for the lower and higher limit of $K_{t}$, respectively. van der Meer, et 
al. [25] and [26] also indicated that incident wave angle has not significant effect on $\mathrm{K}_{\mathrm{t}}$ behind the rubble mound structures.

van Oosten, et al. [34] developed an artificial neural network model for prediction of 2D wave transmission behind submerged structured based on the DELOS database [54]. Similarly, Panizzo and Briganti [27] developed an artificial neural network model for prediction of the wave transmission coefficient behind 2D submerged structures. Both methods produced much better predictions in comparison with existing prediction formula for wave transmission coefficient in 2D conditions. In the study conducted by [27], a total of 2285 tests were employed. Their model was basically an $\mathrm{I}_{6} \mathrm{H}_{6} \mathrm{O}_{1}$ model (i.e. including 6 inputs, 6 hidden units and 1 output). The data sets were as follows: Set 1: including the data from [32]; [56] ; [57]; [58] and [53]) was made up of 354 tests. Set 2: data from [33] which is the largest homogenous dataset available for rubble mound low-crested structures with negative and zero freeboard includes 632 tests. Set 3: data from [32] and [59] includes 236 tests. Set 4: data from [60], which is the largest among those considered in their work, includes 1063 data. These four subsets are independent from each other; other sets were based on combinations of them [27]. An artificial neural network model to predict $\mathrm{K}_{\mathrm{t}}$ behind low-crested structures was developed by [27]. The datasets gathered within the DELOS project were used to train and validate their model, which includes a set of non-dimensional physical parameters. The calibrated and optimised model was found to perform more accurately compared with [26].

Buccino and Calabrese [28] presented semi-empirical models and predictive equations for $\mathrm{K}_{\mathrm{t}}$ behind both submerged and emergent breakwaters based on simplified modelling of wave breaking and overtopping as well as seepage through the body. The results show good agreement with a large ensemble of experimental data. The following is the proposed formula for submerged breakwaters [28]:

$$
K_{t}=\frac{1}{1.18 .\left(\frac{H_{i}}{h_{s}}\right)^{0.12}+0.33 \cdot\left(\frac{H_{i}}{h_{s}}\right)^{1.5} \cdot \frac{B}{\sqrt{H_{i} \cdot L_{o}}}}
$$

$$
\begin{aligned}
& \text { for } \\
& \frac{1}{0.5} \geq\left(\frac{h_{s}}{H_{i}}\right) \geq \frac{1}{1.2} \\
& \text { and } \\
& K_{t}=\left[\min \left(0.74 ; 0.62 . \xi_{o}^{0.17}\right)-0.25 \min \left(2.2 ; \frac{B}{\sqrt{H_{i} \cdot L_{o}}}\right)\right]^{2}
\end{aligned}
$$

where $\mathrm{h}_{\mathrm{s}}=0$.

Goda and Ahrens [29] proposed the following empirical formulae found from wave transmission coefficients derived by [61]:

$$
K_{t}=\max \left\{0,\left(1-\exp \left[a\left(\frac{h_{c}}{H_{i}}-F_{0}\right)\right]\right)\right\}
$$

where

$$
a=0.248 \exp \left[-0.384 \ln \left(\frac{B_{\text {eff }}}{L_{o}}\right)\right]
$$


where $B_{\text {eff }}$ is the effective width of structure and $F_{o}$ represents an approximate limit of dimensionless wave runup which is evaluated [29]:

$$
F_{0}=\left\{\begin{array}{cll}
1.0 & \text { if } & D_{\text {eff }}=0 \\
\max \left\{0.5, \min \left(1.0, \frac{H_{i}}{D_{\text {eff }}}\right)\right\} & \text { if } & D_{\text {eff }}>0
\end{array}\right.
$$

$D_{\text {eff }}$ denotes the effective diameter of the material from which the structure is built, which is taken as the median diameter $\mathrm{D}_{50}$ for rubble stone and $\left(\frac{M_{50}}{\rho_{r}}\right)^{\frac{1}{3}}$ for concrete blocks with $\mathrm{M}_{50}$ being the mass and $\rho_{r}$ being the density. The effective width $B_{\text {eff }}$ of the structure depends on the crest height relative to the still water level [29]:

$$
B_{\text {eff }}=\left\{\begin{array}{cc}
B_{\text {swl }} & \text { emerged crest } \\
\frac{9}{10} B+\frac{1}{10} B_{o} & \text { zero freeboard } \\
\frac{8}{10} B+\frac{2}{10} B_{o} & \text { submerged crest }
\end{array}\right.
$$

where $\mathrm{B}_{\mathrm{swl}}$ is the width at the still water level, $\mathrm{B}$ is the crest width and $\mathrm{B}_{\mathrm{o}}$ is the bottom width.

\section{Data set}

The performance of the ANN scheme depends critically on the data used for training. Insufficient or noisy data can step down the efficiency of the network in predicting the unknown parameters of the phenomenon under study. This section describes preparation of the experimental data set used in this paper. Preparing data in ANN modelling is an essential stage. For an accurate prediction, data preparation should be undertaken firstly to reduce the training time, secondly to meliorate the model simplicity, and thirdly to increase its scope for generalization. In the study reported here, a large number of 2D experiments have been conducted in wave flumes with submerged breakwaters over broad ranges of wave height, period, water depth, submergence depth and distance from the beach. Impermeable breakwater models were constructed to prevent filtration through the structure. This restricted wave transmission to overtopping only. According to a series of tests carried out on solid and rubble mound breakwaters under both regular and irregular wave conditions, Davies and Kriebel [46] found that the solid and rubble-mound submerged breakwaters both have relatively similar wave transmission coefficients. Laboratory data sets collected are listed below [36]:

Data sets:

(a) Set 1 (Training data; Estimation and Validation subsets): This data set is from two different wave tanks both at UCL: (1) a wave flume $20 \mathrm{~m}$ long, $1.2 \mathrm{~m}$ wide and $1 \mathrm{~m}$ deep with a 1:15 sloping beach at one end and (2) a wave flume $14 \mathrm{~m}$ long, $0.45 \mathrm{~m}$ wide and $0.75 \mathrm{~m}$ deep with a false beach at one end. Experiments included various submergence depths, water depths and wave conditions. The data collected in this set were used for ANN model training [36].

(b) Set 2 (Testing data): This data set was collected in the same flumes as Set 1, and within the same range of physical parameters including submergence depths, water depths and wave conditions. The data collected in this set were used to test the ANN model for the accuracy of its predictions [36].

The figure 1 [36] shows a schematic drawing of the wave tank $20 \mathrm{~m}$ by $1.2 \mathrm{~m}$ wide by $1.3 \mathrm{~m}$ high at UCL where 
the first series of experiments were carried out. The figure indicates the location of the probes throughout the tests with and without breakwater [36]. As mentioned above, a second series of experiments was also conducted in a smaller wave tank $14 \mathrm{~m}$ by $0.45 \mathrm{~m}$ by $0.75 \mathrm{~m}$ under various wave conditions, submergence depths and breakwater geometries including width and height but with similar experimental setup, equipments, facilities, location of the wave probes and the method of data sampling throughout the tests as illustrated in Figure 1 for the first series of tests in the wave tank $20 \mathrm{~m}$ by $1.2 \mathrm{~m}$ wide by $1.3 \mathrm{~m}$ high [36].

A total of 176 tests were conducted in the first flume and 180 tests were conducted in the second flume. Eventually, about 1760 data samples were collected from the first series of experiments with the breakwaters and about 1800 data samples were collected from the second series of experiments with the breakwaters [36]. The tests were conducted for various wave conditions, water depths, submergence depths and breakwater geometries including width and height. Only regular waves were considered in the tests [36].

An ideal model is one which explains the problem in the easiest and simplest way using the fewest variables. It is important to identify the variables that save modelling time and space [62]. Based on analysis of the experimental data using both dimensional and non-dimensional parameters, those main input parameters were considered, namely, incident wave height $H_{i}$, offshore wave length $L_{o}$, water depth over the breakwater crest $h_{s}$, water depth in the toe of breakwater $h$, breakwater crest width $B$ and the seaward slope of the breakwater $\alpha$ [36]. Figure 2 shows a simplified diagram of the breakwater and defines the physical parameters.

Table 1 and Table 2 present the spectrum of data employed for training and evaluation of the RBF model including minimum, maximum, mean and standard deviation of each individual parameter expressed in dimensional and non dimensional forms respectively. $K_{t}$ is determined as [36]:

$$
K_{t}=f\left\{\xi_{o}, \frac{H_{i}}{h}, \frac{h_{s}}{H_{i}}, \frac{B}{H_{i}}\right\}
$$

where the first parameter $\xi_{0}$ is Iribarren number which was defined before.

Table 1. The range of training and testing data (dimensional datasets: Set 1 and Set 2)

\begin{tabular}{|c|c|c|c|c|}
\hline Parameter & Mean & $\begin{array}{c}\text { Standard } \\
\text { deviation }\end{array}$ & Min & Max \\
\hline$H_{i}(\mathrm{~mm})$ & 51 & 24 & 10 & 104 \\
\hline$L_{o}(\mathrm{~mm})$ & 1893 & 671 & 976 & 3380 \\
\hline$h_{s}(\mathrm{~mm})$ & 63 & 37 & 0 & 112 \\
\hline$h(\mathrm{~mm})$ & 321 & 85 & 187 & 400 \\
\hline$B(\mathrm{~mm})$ & 374 & 215 & 195 & 800 \\
\hline
\end{tabular}

Table 2. The range of training and testing data (non-dimensional datasets: Set 1 and Set 2)

\begin{tabular}{|c|c|c|c|c|}
\hline Parameter & Mean & $\begin{array}{c}\text { Standard } \\
\text { deviation }\end{array}$ & Min & Max \\
\hline$\xi_{\boldsymbol{o}}$ & 6.64 & 2.25 & 3.71 & 15.45 \\
\hline$H_{i} / h$ & 0.17 & 0.10 & 0.03 & 0.54 \\
\hline$h_{s} / H_{i}$ & 1.69 & 1.61 & 0.00 & 10.73 \\
\hline$B / H_{i}$ & 9.92 & 9.40 & 1.88 & 51.55 \\
\hline
\end{tabular}


Applying dimensionless parameters helps to clarify issues concerning scale effects. To obviate the scaling problem entirely throughout the training, validation and future application of the ANN models, a normalization process is also essential. This can be achieved by applying the following formula [63]:

$$
x_{n}=\frac{x-\min (x)}{\max (x)-\min (x)}
$$

where $x$ represents the parameter to be normalized.

\section{ANN model setup, calibration and performance}

A cross-validation method [64] was employed in this study to deal with the problem of over-fitting during the training process and to improve the generalization for future applications of the model. This involved dividing the data into three subsets, for estimation, validation, and testing. The estimation subset contains data used to train the ANN models, while the validation subset was employed in order to evaluate the manner of functioning of the model and monitor the training process. The training samples were set up to be completely random for an improved learning procedure. The network weights and biases were saved using values giving the minimum error from the validation set. Having been tuned using the entire training data set, the network was verified using the test data not seen before [64]. The data set described in Table 2 was used to train the networks and to investigate the model performance.

The model included a 15-node hidden layer RBF network with Gaussian transfer function in computational units. It included the following non-dimensional parameters: surf similarity parameter $\xi_{o}$, relative wave height $H_{i} / h$, submergence ratio $h_{s} / H_{i}$ and crest width ratio $B / H_{i}$. The output of the ANN model was the wave transmission coefficient $\left(K_{t}\right)$. Performance of the RBF network is examined and predictions are compared with new observations in Section 6. For further details about the RBF network please see the Appendix B.

\section{Classical approaches}

In order to investigate the capability of existing empirical formulae and to highlight the need for a new design tool, analysis is presented below using methods selected from the literature. In particular the 2D empirical formulae presented by [28] and [29] are applied. These formulations will hereinafter be referred to as BC2007 and GA2008 respectively. In order to perform a meaningful comparison, these approaches are tested using experimental data within the same range the models were calibrated.

Figure 3 presents a comparison between the present measurements of $K_{t}$ and 2D predictions for the full range of wave conditions, water depths and breakwater geometries considered. The predictions are calculated using models by [28], [29], and the RBF model. The comparison indicates that the models by [28], [29] do not agree well with the experiments. These analyses confirm the significance of wave transmission behind submerged breakwaters and the need for an accurate and reliable design tool.

We can also quantify the accuracy of these tools by means of five statistical parameters (Table 3). RBF model gives an $R^{2}$ equal to 0.97 and $I_{w}=0.76$ while other models gives much lower values. The error indexes also confirm the more accurate prediction of RBF model than other models (RMSE $=0.07, \varepsilon=0.34$ ). Moreover, the RBF model does not show virtually any bias of the estimate, and the error is symmetrically distributed within the whole range of $\mathrm{K}_{\mathrm{t}}(\beta=1.00)$. However, in comparison with the BC2007, the GA2008 seems to perform better with an $\mathrm{R}^{2}$ equal to 0.86 . 
Table 3: Statistical comparison of RBF model with existing design tools

\begin{tabular}{|c|c|c|c|c|c|}
\hline Statistical index & $I_{w}$ & $\varepsilon$ & $R^{2}$ & $\beta$ & $R M S E$ \\
\hline BC2007 [28] & 0.53 & 0.70 & 0.66 & 1.15 & 0.69 \\
\hline GA2008 [29] & 0.61 & 0.50 & 0.86 & 1.47 & 0.55 \\
\hline RBF & 0.76 & 0.34 & 0.97 & 1.00 & 0.07 \\
\hline
\end{tabular}

Figure 4 presents a comparison between measurements and wave transmission coefficients calculated by the proposed model, along with the [28] and [29] formulations for various non-dimensional input parameters. As can be seen, very similar patterns are observed with the RBF model for all non-dimensional variables, which also confirm the accuracy of predictions by the proposed model in comparison with the two other approaches.

\section{Validity and reliability of the prediction model}

To assess the performance of the trained RBF model, it was applied over a set of data not employed in the training process. The neural networks were trained within a specific range of inputs as defined in Table 2 (Set 1) and were tested for new values of input parameters within the same range (Set 2). A sensitivity analysis was conducted carefully to evaluate the influence of each individual input parameter on the final ANN's outcomes. The results are considered in the next section.

\subsection{Accuracy analysis}

The proposed ANN model in this paper has been compared with the laboratory data measured in two wave flumes described above. The comparison was done using the five statistical parameters [12]: Root Mean Squared Error (RMSE), squared multiple correlation coefficient $\left(R^{2}\right)$, bias or distortion $(\beta)$, Wilmott index $\left(I_{w}\right)[65]$ and error function $(\mathcal{E})[66]$ as below:

$$
\begin{aligned}
& R M S E=\left[\frac{\sum_{i=1}^{N}\left(\frac{X_{c_{i}}-X_{m_{i}}}{X_{m_{i}}}\right)^{2}}{N}\right]^{1 / 2} \\
& R^{2}=\frac{\left(\sum_{i=1}^{N}\left(X_{m_{i}}-\bar{X}_{m}\right)\left(X_{c_{i}}-\bar{X}_{c}\right)\right)}{\sum_{i=1}^{N}\left(X_{m_{i}}-\bar{X}_{m}\right)^{2} \sum_{i=1}^{N}\left(X_{c_{i}}-\bar{X}_{c}\right)^{2}}
\end{aligned}
$$




$$
\begin{aligned}
& I_{w}=1-\frac{\sum_{i=1}^{N}\left(X_{c_{i}}-\bar{X}_{m_{i}}\right)^{2}}{\left.\sum_{i=1}^{N}\left|X_{c_{i}}-\bar{X}_{m}\right|+\left|X_{m_{i}}-\bar{X}_{m}\right|\right)^{2}} \\
& \beta=\frac{\sum_{i=1}^{N}\left(\frac{\left.X_{c_{i}}\right)}{\left.X_{m_{i}}\right)}\right.}{N} \\
& \mathcal{E}=\left[\frac{\sum_{i=1}^{N}\left(X_{c_{i}}-\bar{X}_{m_{i}}\right)^{2}}{\sum_{i=1}^{N} X_{m_{i}}^{2}}\right]^{1 / 2}
\end{aligned}
$$

where $N$ represents the number of samples in each group and where $X_{c}$ is the calculated values, $X_{m}$ is the measured values and the barred parameters demonstrate the average values of the parameters [67].

Perfect agreement is achieved if $\mathrm{R}^{2}$ and Wilmott index are 1.0 and the error function is zero. The values of distortion closer to 1.0 and the lower values of RMSE also indicate better performance. $\mathrm{R}^{2}$ is considered unsatisfactory as a measure of the goodness of fit for a multivariate regression relationship [67] and thus the validity of the model will be assessed mostly by the other parameters.

All of the efficiency criteria for model assessment contain their own advantages and disadvantages. The most used one is coefficient of determination, $\left(\mathrm{R}^{2}\right)$ [68]. This method is very sensitive to outliers. Also, from previous studies, it has been shown that $\mathrm{R}^{2}$ alone is not sufficient for model assessment because it is based simply on correlation. So $\mathrm{R}^{2}$ should be used along with other criteria [68].

Calculated values of the five statistical indexes are provided in Table 4. These indicate that the ANN model is able to calculate wave transmission coefficient with reasonable accuracy. $R^{2}$ is fairly high (higher than 0.95$)$ and also Wilmot number $I_{w}$ (higher than 0.75). With $\beta(\approx 1)$ and low values of $\varepsilon(=0.24)$ and RMSE (less than 0.05) there is clearly good agreement with of the experiments.

The predictions of transmission coefficients obtained by the RBF model when plotted against the corresponding observed data (Fig.5) show the good agreement. The error distribution is also shown in Figure 5, using a notched box-and-whisker plot ([69], [70]) indicating the degree of dispersion (spread) and skewness in $K_{t}$, as well as identifying outliers. The error notched box-and-whisker plot in Fig. 5 illustrates the good performance of the RBF model for each error data category.

Table 4: Statistical evaluation of RBF model

\begin{tabular}{|c|c|c|c|c|c|}
\hline Statistical index & $I_{w}$ & $\varepsilon$ & $R^{2}$ & $\beta$ & $R M S E$ \\
\hline RBF model & 0.78 & 0.24 & 0.97 & 0.99 & 0.04 \\
\hline
\end{tabular}


Figure 6 illustrates the error from the RBF model in a different way for the four non-dimensional input variables. Figure 6 (a) demonstrates the distribution of computed error over the whole range of values of surf similarity parameter $\xi_{o}$. For most of the range, the average error is below $10 \%$. Higher errors are seen for $\xi_{o}$ between 4 and 6 . Regarding the nondimensional wave height $H_{i} / h$, the error is found to decrease for increasing $H_{i} / h$. Except for a few points between 0.05 and 0.25 which have a high error, the average error over most of the range is below $10 \%$. For points with submergence ratio $h_{s} / H_{i}$ between 1 and 3 , large computed errors can be observed while, for other values, error is mostly less than $10 \%$. Errors obtained for different values of crest width ratio $B / H_{i}$ are mostly less than $10 \%$, except for a few points where $B / H_{i}$ is less than 10 . The large scatter of values observed within some ranges is a consequence of the limited data points within those ranges.

Figure 7 shows a comparison between calculated wave transmission coefficients using the proposed model and measured values for various non-dimensional input parameters. As can be seen, very similar patterns are observed in all cases for all non-dimensional variables which also confirm the accuracy of predictions by the RBF model.

\subsection{Sensitivity analysis}

As the influence of all relevant parameters involved in wave transmission modelling behind 2D submerged breakwater is included simultaneously in the present ANN model, to identify the influence of each parameter and its effect on performance of model, networks were designed and trained using the same training data set but with the omission of each parameter in order that the most effective parameter could be introduced. Assessments were made of the performance of the networks by comparison of network results using the statistical parameters. This investigation (Table 5) illustrated that $\xi_{o}$ and $H_{i} / h$ with the least correlation coefficient $(0.93,0.94)$ and the highest error $(\mathrm{RMSE}=0.21,0.28)$ are the most influential parameters in the wave transmission behind breakwater. It should be mentioned that dividing the whole data set into estimation subset, validation subset and testing subset for the sensitivity analysis was carried out in the same way as the division for the construction of the main ANN model. The $\mathrm{R}^{2}$ correlation coefficient and RMSE values for the main ANN model are 0.97 and 0.04 respectively.

Table 5: Sensitivity analysis for RBF model

\begin{tabular}{|c|c|c|c|c|}
\hline Omitted parameter & $\xi_{o}$ & $H_{i} / h$ & $h_{s} / H_{i}$ & $B / H_{i}$ \\
\hline$R^{2}$ & 0.93 & 0.94 & 0.94 & 0.97 \\
\hline$R M S E$ & 0.21 & 0.28 & 0.13 & 0.10 \\
\hline
\end{tabular}

A detailed sensitivity analysis is also presented in Figure 8 comprising different sensitivity graphs of individual non-dimensional input parameters. The sensitivity figures contain several lines. The dash lines show the band of the 95\% confidence interval, one line for the lower boundary (quartile 2.5\%) and the other for the upper boundary (quartile 97.5\%). The solid line is the ANN prediction (mean value). Figure 8 (a) reveals that the ANN model gives a relatively high reliability in the range of $x_{0}<12.4$. Outside this interval the model tends to low reliability. Figure 8 (b) shows that the model is also reliable in the range $\mathrm{H}_{\mathrm{i}} / \mathrm{h}<0.45$. Based on Figure 8 (c), the model is reliable in the range $h_{s} / H_{i}<7.2$. For larger submergence depth the ANN model is rather unreliable. According to this plot, $K_{t}$ increases dramatically with submergence ratio from a value of $\mathrm{K}_{\mathrm{t}}=0.1$ at zero submergence to a value of $\mathrm{K}_{\mathrm{t}}=0.73$ at $\mathrm{h}_{\mathrm{s}} / \mathrm{H}_{\mathrm{i}}=6$. Beyond this point, no significant influence of the submergence ratio is seen. There is a narrow confidence band with high reliability in Figure 8 (c) for $0<\mathrm{h}_{\mathrm{s}} / \mathrm{H}_{\mathrm{i}}<4$. It can be observed from the Figure 8 (d), the model seems to be reliable for $\mathrm{B} / \mathrm{H}_{\mathrm{i}}$ values up to 27 . For greater values, the model still has acceptable reliability.

According to the physical observations, an increase in the submergence ratio results in a decrease in the wave transmission coefficient. The results obtained show a similar trend. Within the range $0<\mathbf{h}_{\mathbf{s}} / \mathbf{H}_{\mathbf{i}}<4$, a clear trend can be observed. The confidence band within this range is narrow. This trend is also seen within the range $\mathbf{h}_{\mathbf{s}} / \mathbf{H}_{\mathbf{i}}<7.2$, although for $\mathbf{h}_{\mathbf{s}} / \mathbf{H}_{\mathbf{i}}>7.2$ the model gives a physically unreliable prediction, which is caused by the limited number of data samples within this range. Higher errors are observed for larger values of $\mathrm{B} / \mathrm{H}_{\mathrm{i}}$. It should be noted that data points with $\mathrm{B} / \mathrm{H}_{\mathrm{i}}<27$ are more frequent in the database. 


\section{Conclusions}

Comparisons reveal encouraging performance and reliable predictions from the RBF model and illustrate that the model has the potential to be employed in a broad spectrum of practical applications. The sensitivity analysis showed that the non-dimensional parameters $\xi_{o}$ and $H_{i} / h$ were the most effective in describing the process. When these parameters were excluded from the training of the network, the lowest correlation coefficients and the greatest errors were obtained. A restricted range of input parameters has been found to give more reliable and valid predictions while out of this range the results are still reasonable. A $\mathrm{K}_{t}$ calculator is presented, based on the proposed non-dimensional RBF model. A step by step procedure for practical applications is outlined in a user-friendly form with the intention of providing a simplified tool for preliminary design purposes which can be used in submerged breakwater design. Applying the proposed ANN model for predictions, guidance is given to predict $\mathrm{K}_{\mathrm{t}}$ behind submerged breakwaters. It is concluded that the proposed model offers potential as a design tool to predict wave transmission coefficients behind submerged breakwaters.

The proposed model could be applied in real practical applications with high reliability by engineers and scientists as a more precise and dependable design tool than existing models. The results of this study can be applied not only for wave modelling behind submerged structures but also in flow models around these structures by importing the wave data in to the available models and calculating flow patterns behind such structures. Although the model is calibrated and designed using regular wave data, similar prediction could be achieved using Significant Wave Height $\left(\mathrm{H}_{\mathrm{s}}\right)$ or Zero Moment Wave Height $\left(\mathrm{H}_{\mathrm{mo}}\right)$ for incident wave height and the peak wave period, $\mathrm{T}_{\mathrm{p}}$ for wave period for irregular waves. Given the availability of training data, the model has the capability to be extended to include other physical parameters such as other breakwater geometries and shapes, distance to the shore line, seabed slope, etc can be tested in the laboratory.

\section{Appendix A.}

\section{A simplified tool and initial prediction scheme with a step by step procedure $\left(\mathrm{K}_{\mathrm{t}}\right.$ calculator)}

The algorithm used in this appendix is based closely on the algorithm introduced by [12] and the later work by [36].

As explained in Section 5, the final optimized RBF network has one radial basis function layer with 15 nodes. A $\mathrm{K}_{\mathrm{t}}$ calculator including details about the model mathematics is described below, based on the proposed nondimensional RBF model. A step-by-step procedure for practical applications is outlined in a user-friendly form ([12] and [36]) with the intention of providing an initial prediction scheme according to the proposed ANN model described in the paper. For more details and theoretical aspects see [63] or [64].

Referring first to the non-dimensional parameters used throughout the paper, an input vector $I$ should be considered:

$$
I=\left[\xi_{o}, H_{i} / h, h_{s} / H_{i}, B / H_{i}\right]
$$

The normalization process according to the Eq. 7 is performed:

$$
I_{n}=\left(I-I_{\min }\right) /\left(I_{\max }-I_{\min }\right)
$$

where vectors $I_{\min }, I_{\max }$ are characterized by values:

$$
\begin{gathered}
I_{\min }=[3.7066,0.0348,0.0000,1.8775] \\
I_{\max }=[15.4525,0.5384,10.7259,51.5480]
\end{gathered}
$$

Considering the center and weight matrices defined below, the input signals are passed through the network. The center matrix $c$ and weight vector $w$ are applied in the transfer functions Eq. (A.7) and Eq. (A.11) respectively. 
The values in the last column of the center matrix $c$ and the weight vector $w$ are the bias values for the hidden and output layers respectively.

$$
\begin{aligned}
& c=\left(\begin{array}{lllll}
0.8994 & 0.0000 & 1.0000 & 0.3382 & 0.8326 \\
0.6765 & 0.0093 & 0.2950 & 0.8542 & 0.8326 \\
0.6631 & 0.0115 & 0.5742 & 0.7062 & 0.8326 \\
0.5942 & 0.0086 & 0.2979 & 0.8629 & 0.8326 \\
0.4123 & 0.0193 & 0.7819 & 0.2562 & 0.8326 \\
0.4341 & 0.0269 & 0.2410 & 0.5867 & 0.8326 \\
0.4268 & 0.0288 & 0.4728 & 0.4726 & 0.8326 \\
0.7090 & 0.0868 & 0.0000 & 0.2296 & 0.8326 \\
1.0000 & 0.0433 & 0.4084 & 0.2396 & 0.8326 \\
0.5901 & 0.0093 & 0.2952 & 0.9821 & 0.8326 \\
0.2849 & 0.0608 & 0.5321 & 0.1623 & 0.8326 \\
0.3095 & 0.0954 & 0.1406 & 0.1444 & 0.8326 \\
0.4292 & 0.0977 & 0.1350 & 0.1727 & 0.8326 \\
0.6522 & 0.0133 & 0.5615 & 0.9322 & 0.8326 \\
0.3449 & 0.1031 & 0.0000 & 0.2043 & 0.8326
\end{array}\right) \\
& w=\left\{\begin{array}{llllllll}
35.2393 & -186.0468 & -179.6246 & 733.9377 & -66.3753 & -180.8649 & 57.2453 & -2.2679
\end{array}\right. \\
& \begin{array}{llllllll}
-2.3436 & -379.9198 & 85.0211 & -76.2526 & 39.5692 & 93.4942 & 29.6973\} & \text { (A.6) }
\end{array}
\end{aligned}
$$

Activation functions of radial basis type are used to determine the values of hidden neurons, such as:

$$
a_{1}(i, 1)=\exp \left(-\left(\operatorname{dist}\left(c(i,:), a_{o}\right) \cdot d\right)^{2}\right) ; \quad \text { for } i: 1 \ldots 15
$$

where

$$
a_{o}(5,1)=1
$$

and constant value $d$ is:

$$
d=\operatorname{sqrt}(-\log (.5)) / s p
$$

where $s p=1.0$.

The Euclidean distance between the vectors $a_{o}$ and $c$, is defined as follows:

$$
\operatorname{dist}\left(\mathrm{c}_{\mathrm{i}}-\mathrm{a}_{\mathrm{o}, \mathrm{i}}\right)=\sqrt{ }\left(\sum\left(\mathrm{c}_{\mathrm{i}}-\mathrm{a}_{\mathrm{o}, \mathrm{i}}\right)^{2}\right) \quad \text { for } i: 1 \ldots .5 \quad \text { (A.10) }
$$

where $c_{i}$ and $a_{o, i}$ are the coordinates of $c$ and $a_{o, i}$ in dimension $i$.

Whereas a linear activation function has been applied, the scaled model outcome can be computed as follows:

$$
a_{2}=w \cdot a_{1}+b_{2} \quad(A .11)
$$

where $b_{2}=-0.3438$ is the bias neuron for the output layer.

Finally, the model output needs to be rescaled. Thus, $K_{t}$ is calculated as follows:

$$
K_{t}=\left(O_{\max }-O_{\min }\right) \cdot * a_{2}+O_{\min } \quad(A .12)
$$

where $O_{\min }=0.1187$ and $O_{\max }=0.8416$. 
The main aim is to introduce a simplified tool for preliminary design purposes which can be used in submerged breakwater design. Although the model is calibrated and designed using regular wave data, similar predictions can be made using significant wave height $\left(H_{s}\right)$ /zero moment wave height $\left(H_{m o}\right)$ and peak wave period, $T_{p}$ as inputs. However, some considerations might be required in applying regular wave results to random sea-states ([12] and [36]).

\section{Appendix B.}

\section{Radial basis function (RBF) network}

This appendix gives a concise description of the training algorithm adopted in this paper for the RBF network.

In engineering applications, the most popular artificial neural network is the multi-layer perceptron (MLP). Radial basis function (RBF) networks with universal non-linear approximation properties are similar to the multilayer perceptron in that they also use memory-based learning algorithms for their design ([71], [63]).

RBF networks are used widely for non-linear function approximation comparable to MLP networks ([72],[73]), with some additional benefits, for instance, RBFs are trained usually with a relatively higher speed [74]. The concept of a RBF neural network was introduced by [72]. In the same way as for a MLP network, the entire data set is split into two main data sets and training and testing performed in two distinct stages ([72], [73]).

While the number of layers in MLP can be variable, RBF networks are always designed with three layers of neurons: input layer, hidden layer and output layer. Working as a feed-forward RBF network: the input layer receives the input data, the hidden layer computes the outcome of the RBF units and the output layer combines the outputs from the RBF units linearly. The input and output layers in a RBF network are thus the same as in MLP, while the hidden layer is not. The main difference is related to the transfer functions applied in the hidden layer. The Euclidean distance between the input vector and the RBF unit's centre vector $c$ is calculated in the RBF networks while an MLP unit applies a transfer function which computes the inner product of the weight and the input vectors [63].

RBF models include biases in their hidden and output layers similar to MLP. However, RBF models usually have more computational units in the hidden layer than MLP as their transfer functions respond to a smaller area of the input space than MLP. This is of benefit as it requires less training time to design RBF compared with MLP. The outputs are also weighted. Hence, an expression of the RBF network can be presented as [75]:

$$
y(\widehat{x})=\sum_{k=1}^{n} w_{k} \phi\left(\left\|\widehat{x}-c_{k}\right\|\right)+b
$$

where $\hat{x}$ is the input vector, $w_{1}, w_{2}, \ldots, w_{n}$ are weight factors, $\mathrm{c}_{\mathrm{k}}$ represents the centre of the $\mathrm{k}^{\text {th }} \mathrm{RBF}$ unit, $b$ is bias value and $\Phi$ is the hidden layer transfer function (Gaussian function):

$$
\phi\left(\left\|\widehat{x}-c_{k}\right\|\right)=e^{-\left(\left\|\widehat{x}-c_{k}\right\|^{2} / 2 s_{k}^{2}\right)}
$$

where $s_{k}$ is the scaling factor of the $k^{\text {th }}$ RBF unit [75].

Basically, the learning process in RBF networks is a form of supervised learning. Determining and making an appropriate decision on the number of computational neurons is basically an essential step since it influences the network complexity and its generalizing capability. Insufficient computational units mean the RBF network may not estimate the underlying function adequately. However, increasing the size of hidden layer (number of the computational neurons) may cause an overlearning situation [76]. In addition, carefully specifying the optimal locations of the centres and scaling factors in the computational neurons of the hidden layer would be important tasks over the training process and very essential to obtain proper results. The most preferred form of transfer 
functions for a computational neuron is the Gaussian function ([75], [77], [78]).

The next step is for the weights of the network to be computed. At last, the bias values added to each output are calculated. A derivative-based gradient descent algorithm [78] is used in this study, chosen from the various algorithms proposed in the literature for training RBF networks.

Following the training procedure and having decided on the number of hidden units, $c, s, w$ and $b$ parameters are determined. The sum of squared errors (SSE) is typically applied over the training process to check the manner of functioning of the RBF network and is defined as follows [79]:

$$
E(c, s, w, b)=\sum_{j=1}^{J}\left(y_{j}-\hat{y}_{j}\right)^{2}
$$

where $y$ and $\hat{y}$ are the actual and desired outputs respectively.

The training procedure for a RBF network is organised using the following procedure [63]. The hidden layer initially has zero number of units. Data samples are presented to the network, signals pass through the network and the error is computed. The calculated output is compared to the target value of the respective sample. An RBF unit is added. The process is performed repeatedly and the connection weight parameters are then computed to meet the desired error. Basically, the calculated error, which is statistically described as the sum of squared errors (SSE), must be lower than the desired error. In addition, the maximum number of hidden neurons should be met before stopping training [63].

In the present case in this study, a 15-node hidden layer network was chosen. The training of the RBF model was terminated once the calculated error reached the desired values (in this study 0.01) or the chosen number of training iterations (here 100) had been completed.

\section{References}

[1] Huang, W-P, Chou, C-R, Yim, J-Z, (2005). On reflection and diffraction due to a detached breakwater, Ocean Engineering, Volume 32, Issues 14-15, Pages 1762-1779.

[2] Ilic, S., van der Westhuysen, A.J., Roelvink, J.A., Chadwick, A.J., (2007). Multidirectional wave transformation around detached breakwaters, Coastal Engineering, Volume 54, Issue 10, Pages 775-789.

[3] Du, Y., Pan, S., Chen, Y., (2010). Modelling the effect of wave overtopping on nearshore hydrodynamics and morphodynamics around shore-parallel breakwaters, Coastal Engineering 57 (9), 812-826.

[4] Kristensen, S-E, Drønen, N., Deigaard, R., Fredsoe, J., (2013). Hybrid morphological modelling of shoreline response to a detached breakwater, Coastal Engineering, Volume 71, Pages 13-27.

[5] Hur, D-S, (2004). Deformation of multi-directional random waves passing over an impermeable submerged breakwater installed on a sloping bed, Ocean Engineering, Volume 31, Issue 10, Pages 1295-1311.

[6] Jeng, D.-S., Schacht, C., Lemckert, C., (2005). Experimental study on ocean waves propagating over a submerged breakwater in front of a vertical seawall, Ocean Engineering, Volume 32, Issues 17-18, Pages 22312240 .

[7] Tsai, C-P, Chen, H-B., Lee, F-C, (2006). Wave transformation over submerged permeable breakwater on porous bottom, Ocean Engineering, Volume 33, Issues 11-12, Pages 1623-1643.

[8] Wang B.X., Otta A.K., Chadwick A.J. (2007). Transmission of obliquely incident waves at low-crested breakwaters: Theoretical interpretations of experimental observations Coastal Engineering 54 (4), pp 333 - 344.

[9] Zanuttigh, B., Martinelli, L., Lamberti, A., (2008). Wave overtopping and piling-up at permeable low crested structures. Coastal Engineering 55, 484_498.

[10] Calabrese, M., Vicinanza, D., Buccino, M., (2008). 2D Wave setup behind submerged breakwaters, Ocean 
Engineering, Volume 35, Issue 10, Pages 1015-1028, ISSN 0029-8018.

[11] Zhang, J.-S., Jeng, D.-S., Liu, P.L.-F., Zhang, C., Zhang, Y., (2012). Response of a porous seabed to water waves over permeable submerged breakwaters with Bragg reflection, Ocean Engineering, Volume 43 Pages 1-12.

[12] Sharif Ahmadian, A., Simons, R.R., 2014. A 3D numerical model of nearshore wave field behind submerged breakwaters. Coast. Eng. 83, 190-204. Available from: http://dx. doi.org/10.1016/j.coastaleng.2013.10.016.

[13] Lee, T-L, Jeng, D-S, (2002). Application of artificial neural networks in tide-forecasting, Ocean Engineering, Volume 29, Issue 9, Pages 1003-1022.

[14] Huang, W., Murray, C., Kraus, N., Rosati, J., (2003). Development of a regional neural network for coastal water level predictions, Ocean Engineering, Volume 30, Issue 17, Pages 2275-2295.

[15] Kim, D-H, Park, W-S, (2005). Neural network for design and reliability analysis of rubble mound breakwaters, Ocean Engineering, Volume 32, Issues 11-12, Pages 1332-1349.

[16] Rao, S., Mandal, S., (2005). Hindcasting of storm waves using neural networks, Ocean Engineering, Volume 32, Issues 5-6, Pages 667-684.

[17] Lee, T-L, (2006). Neural network prediction of a storm surge, Ocean Engineering, Volume 33, Issues 3-4, Pages 483-494.

[18] van Gent M.R.A., van den Boogaard H.F.P., Pozueta, B., Medina, J.R., (2007). Neural network modelling of wave overtopping at coastal structures, Coastal Engineering Vol. 54, (8), pp. 586-593.

[19] Cha, D., Zhang, H., Blumenstein, M., (2011). Prediction of maximum wave-induced liquefaction in porous seabed using multi-artificial neural network model, Ocean Engineering, Volume 38, Issue 7, Pages 878-887.

[20] Kim, D-H, Kim, Y-J, Hur, D-S, (2014). Artificial neural network based breakwater damage estimation considering tidal level variation, Ocean Engineering, Volume 87, Pages 185-190.

[21] A new approach for deriving temperature and salinity fields in the Indian Ocean using artificial neural networks - by Prasad K. Bhaskaran, R. Rajesh Kumar, Rahul Barman, and M. Ravichandran, Journal of Marine Science and Technology 15(2):160-175, June 2010.

[22] Travel Time Atlas and the Role of Neural Networks for an Early Warning System for Tsunamis in the Indian Ocean - Prasad Kumar Bhaskaran, Rajesh Kumar, S.K. Dube, T.S.Murty, Avijit Gangopadhyay, A.Chaudhuri and A.D.Rao. Conference Paper, Dec 2008.

[23] Tsunami early warning System - an Indian Ocean perspective, Prasad K. Bhaskaran and r. Rajesh Kumar, Journal of Earthquake and Tsunami.

[24] Tsunami travel time prediction using neural networks - by Rahul Barman, B. Prasad Kumar, P C Pandey, S K Dube et al - Geophysical Research Letters, Vol. 33, L16612, doi:10.1029/2006GL026688, 2006.

[25] van der Meer, J., Briganti, R., Wang, B., Zanuttigh, B., (2004). Wave transmission at low-crested structures, including oblique wave attack. Proc. 29th Int. Conf. on Coastal Engineering, ASCE 41, 52 - 64.

[26] van der Meer, J. W., Briganti, R., Zanuttigh, B., Wang, B., (2005). Wave transmission and refection at lowcrested structures: Design formulae, oblique wave attack and spectral change. Coastal Engineering 52, 915 - 929.

[27] Panizzo, A., Briganti, R. (2007). Analysis of wave transmission behind low-crested breakwaters using neural networks. Coastal Engineering, 54(9), pp. 643 - 656.

[28] Buccino, M., Calabrese, M. (2007). Conceptual approach for prediction of wave transmission at low-crested breakwaters. Journal of Waterway, Port, Coastal and Ocean Engineering, 133(3), pp.213 - 224.

[29] Goda Y. and Ahrens, J.P., (2008). New formulation of wave transmission over and through low-crested structures. Proceedings of the 31st International Conference of Coastal Engineering, 4. 
[30] Kurban, T. and Beşdok, E. (2009). A Comparison of RBF Neural Network Training Algorithms for

Inertial Sensor Based Terrain Classification, Sensors, 9, 6312-6329; doi:10.3390/s90806312

[31] Adams, C. and Sonu, C. (1987) Wave Transmission Across Submerged Near-Surface Breakwaters. Coastal Engineering 1986: pp. 1729-1738. doi: 10.1061/9780872626003.126

[32] d'Angremond, K., van der Meer, J., De Jong, R., 1996. Wave transmis-sion at lowcrested structures. Proc. 25th Int. Conf. on Coastal Engineering, ASCE 24, 18_27.

[33] Seabrook, S., Hall, K., 1998. Wave transmission at submerged rubblemound breakwaters.

Proc. 26th Int. Conf. on Coastal Engineering 2, 2000_2013.

[34] van Oosten, R., Peixo Marco, J., van der Meer J.W., Verhagen, H., 2006. Wave transmission

at low-crested structures using neural networks. International conference on

Coastal Engineering, San Diego ASCE, 4932_4944.

[35] Sharif Ahmadian, A., Simons, R.R., 2012. 3-D Wave Field Around Submerged Breakwater. ASCE, New York. Available from: http://dx.doi.org/10.9753/icce.v33. structures.13.

[36] Sharif Ahmadian, A., 2016. Numerical Models for Submerged Breakwaters, 1st Edition

Coastal Hydrodynamics and Morphodynamics. Elsevier

[37] Stucky, A., Bonnard, D., 1937. Contribution to the experimental study of marine

rock fill dikesbull. Tech. rep., Technique de Suizze Romande.

[38] Beach-Erosion-Board, 1940. A model study of the effect of submerged breakwaters on wave action. Technical memorandum No. 1. Chief of Engineers, U.S. War Dept.

[39] Morison, J., 1949. Model study of wave action on underwater barriers. Tech. rep.,

Report HE-116-304, Inst. Eng. Res., Univ. Calif., Berkley.

[40] Johnson, J. W., Fuchs, R. A., Morison, J. R., 1951. The damping action of submerged

breakwaters. Transactions, American Geophysical Union, Volume 32, Issue 5, p.

704-718.

[41] Goda, Y., Takeda, H., Moriya, Y., 1967. Laboratory investigation on wave transmission over breakwaters. Report of the port and Harbour Research Institute 13, 38.

[42] Goda, Y., 1969. Re-analysis of laboratory data on wave transmission over breakwaters.

Report of the port and Harbour Research Institute 18 (3), 3_18.

[43] Seelig, W., 1980. Two-dimensional tests of wave transmission and reflection characteristics

of laboratory breakwaters. Tech. rep., Technical report, CERC, Fort Belvoir,

Report No. 80-1.

[44] Allsop, N., 1983. Low-crested breakwaters, studies in random waves. Proc. Coastal

Structure 83 ASCE, 94_107.

[45] Ahrens, J., 1987. Characteristics of reef breakwaters. Technical Report CERC-87-17,

45.

[46] Davies, B., Kriebel, D., 1992. Model testing on wave transmission past low crested 
breakwaters. Proc. 23th Int. Conf. on Coastal Engineering ASCE, 1115_1128.

[47] Daemrich, K., Kahle, W., 1985. Schutzwirkung von unterwasser wellen brechern unter dem einfluss unregelmassiger seegangswellen. Tech. rep., Technical Report, Franzius Instituts fur Wasserbau und Kusteningenieurswesen, Report Heft 61 (in Germany).

[48] Powell, K., Allsop, N., 1985. Low-crested breakwaters, hydraulic performance and stability. Tech. rep., Technical report SR 57, HR Wallingford.

[49] van der Meer, J., 1988. Rock slopes and gravel beaches under wave attack. Tech. rep., PhD. Thesis, Delft University of Technology, Delft Hydraulics Report No. 396.

[50] Daemen, I., 1991. Wave transmission at low crested structures. Ph.D. thesis, MSc. Thesis, Delft University of Technology, Faculty of Civil Engineering, Delft Hydraulics Report H 462.

[51] Seabrook, S., Hall, K., 1997. Effect of crest width and geometry on submerged breakwater performance. Proc. Canadian Coastal Conference CCSEA, 58_72.

[52] Bleck, M., Oumeraci, H., 2002. Hydraulic performance of arti_cial reefs: Global and local description. Proc. 28th Int. Conf. on Coastal Engineering ASCE, 1778_1790.

[53] Calabrese, M., Vicinanza, D., M., B., 2002. Large-scale experiments on the behaviour of low crested and submerged breakwaters in presence of broken waves. Proc. 28th Int. Conf. on Coastal Engineering ASCE, 1900_1912.

[54] Kramer, M., Zanuttigh, B., Vandermeer, J., Vidal, C., Gironella, F., 2005. Laboratory experiments on low-crested breakwaters. Coastal Engineering 52, 867_885.

[55] van der Meer, J., 1991. Stability and transmission at low-crested structures. Tech. rep., Technical report, Delft Hydraulic, Report No. H 453. 33p.

[56] van der Meer, J. and Daemen, I. (1994). "Stability and Wave Transmission at Low-Crested Rubble-Mound Structures." J. Waterway, Port, Coastal, Ocean Eng., 10.1061/(ASCE)0733-950X(1994)120:1(1), 1-19.

[57] Gironella, X., Sanchez-Arcilla, A., Brigantti, R., Sierra, J. P., Moreno, L., 2002.

Submerged detached breakwaters: towards a functional design. In: Proceedings of 28th Coastal Engineering Conference. Cardi_, Wales, UK, 1768-1777.

[58] Garcia, N., Lara, J., Losada, I., 2004. 2-d numerical analysis of near-field flow at low-crested permeable breakwaters. Journal of Coastal Engineering 51, 991_1020.

[59] Melito, I., Melby, J., 2002. Wave runup,transmission, and reflection for structures armored with core-loc. Journal of Coastal Engineering 42, 33_52.

[60] Hirose, N., Watanuki, A., Saito, M., 2002. New type units for artificial reef development of ecofriendly artificial reefs and the effectiveness thereof. In: Proc. 30th International Navigation Congress. PIANC, p. Cd ROM.

[61] Tanaka, N., 1976. Wave deformation and beach stabilization capacity of wide-crested submerged breakwaters. In: Proc. 23rd Japanese Conf. Coastal Eng. pp. 152-157 
(in Japanese).

[62] Stein, R., (1993). Selecting data for neural networks. AI Expert 8, no. 2, 42 - 47.

[63] Haykin,. S., (1999). Neural Networks, a Comprehensive Foundation, 2nd edn. Prentice Hall, New Jersey.

[64] Hagan, M.T., Demuth, H.B., Beale, M.H., (1996). Neural network design, PWS Publication.

[65] Wilmott,. C.J. (1981). On the validation of models, Progress in Physical Geography, 2, 184-194.

[66] Haller, M.C., Darlymple, R.A. and Svendsen, I.A. (2002). Experimental study of nearshore dynamics on a barred beach with rip channels. Journal of Geophysical Research, Vol. 107, C6, 14-1 - 14-21.

[67] Draper, N. R., (1984). The Box-Wetz criterion versus R2. Journal of Statistical Society, 147, 100-103.

[68] Krause, P., Boyle , D. P. and Base, F., (2005) Comparison of different efficiency criteria for hydrological model assessment, Advances in Geosciences, 5, 89-97, 2005 SRef-ID: 1680-7359/adgeo/2005-5-89

[69] Tukey, J. W. (1977). Box-and-Whisker Plots, in Explanatory Data Analysis. Reading, MA: AddisonWesley, pp. 39-43.

[70] McGill, R., Tukey, J. W., and Larsen, W. A., (1978). Variations of Boxplots, The American Statistician, Vol. 32, pp.12-16.

[71] Park, J., and Sandberg, I. W., (1993). Approximation and radial-basis function networks, Neural computation, vol. 5, pp. 305-316.

[72] Broomhead, D. and Lowe, D., (1988). Multivariable functional interpolation and adaptive networks. Comple Systems, 2, 321-355.

[73] Poggio, T., and Girosi, F., (1990). Networks for approximation and learning, Proc. IEEE, vol. 78, pp. 14811497.

[74] Hamadneh, N., Sathasivam S., and Choon, O.H., (2012). Higher Order Logic Programming inRadial Basis Function Neural Network, Applied Mathematical Sciences, Vol. 6, no. 3, 115 - 127.

[75] Robert, J. and Howlett, L.C.J., (2001). Radial basis function networks 2: New Advances in Design. PhysicaVerlag: Herdelberg, Germany.

[76] Liu, Y., Zheng, Q., Shi, Z., Chen, J., (2004). Training radial basis function networks with particle swarms. Lecture Notes Computer Science 3173, 317 - 322.

[77] Simon, D., (2002). Training radial basis neural networks with the extended kalman filter. Neurocomputing $48,455 \_475$.

[78] Karayiannis, N. B., (1999). Reformulated radial basis neural networks trained by gradient descent. IEEE Transactions on Neural Networks 10(3), 657 - 671.

[79] Bullinaria, J., (2004). Introduction to Neural Networks: Lecture notes.

\section{Figure Captions}

Figure 1: Wave tank layout and wave probe positions for a 2D test with $190 \mathrm{~mm}$ breakwater crest width, 300mm water depth at the toe of the breakwater and $112 \mathrm{~mm}$ submergence depth (All measurements in $\mathrm{cm}$ ) [36]

Figure 2: Section of the submerged breakwater and definition of parameters

Figure 3: Graphical comparison of RBF model with existing design tools 
Figure 4: Variation of wave transmission coefficient with (a) $\xi_{0}$, (b) $H_{i} / h$, (c) $h_{s} / H_{i}$, and (d) $B / H_{i}$ for Measured data, RBF model, GA2008 and BC2007 formulations

Figure 5: Graphical comparison between predictions of $K_{t}$ from the RBF model and measured data using a scatter and box-and-whisker plots (dataset: Set 2)

Figure 6: Error computed by ANN model vs. (a) $\xi_{o}$, (b) $H_{i} / h$, (c) $h_{s} / H_{i}$, and (d) $B / H_{i}$

Figure 7: The variation of $K_{t}$ with (a) $\xi_{o}$, (b) $H_{i} / h$, (c) $h_{s} / H_{i}$, and (d) $B / H_{i}$ compared with measured values

Figure 8: Sensitivity analysis of the ANN model to the different nondimensional input parameters 

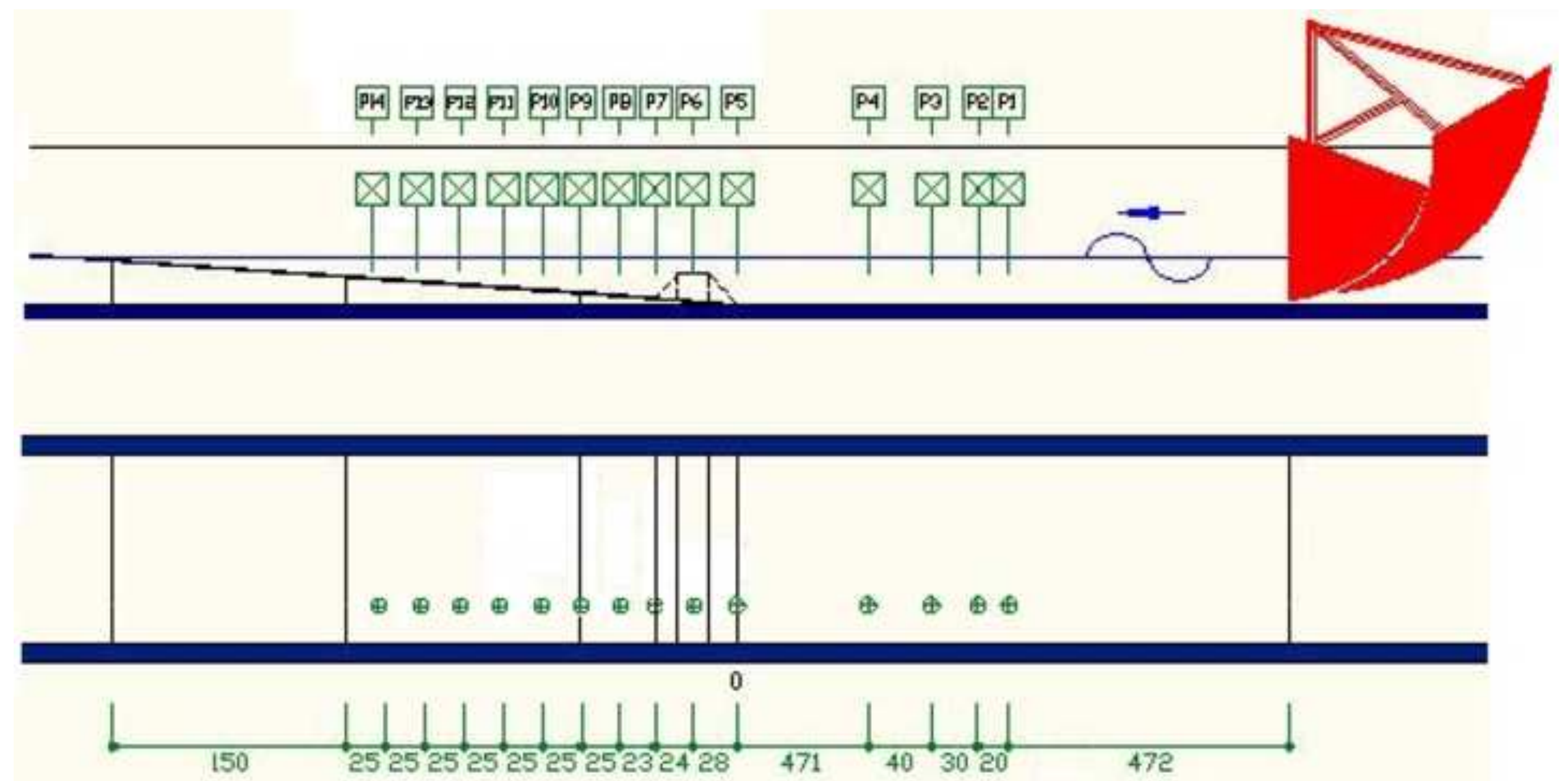

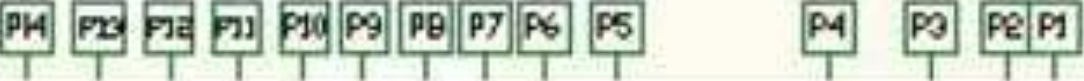

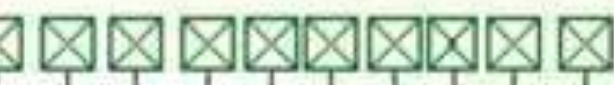

(1)




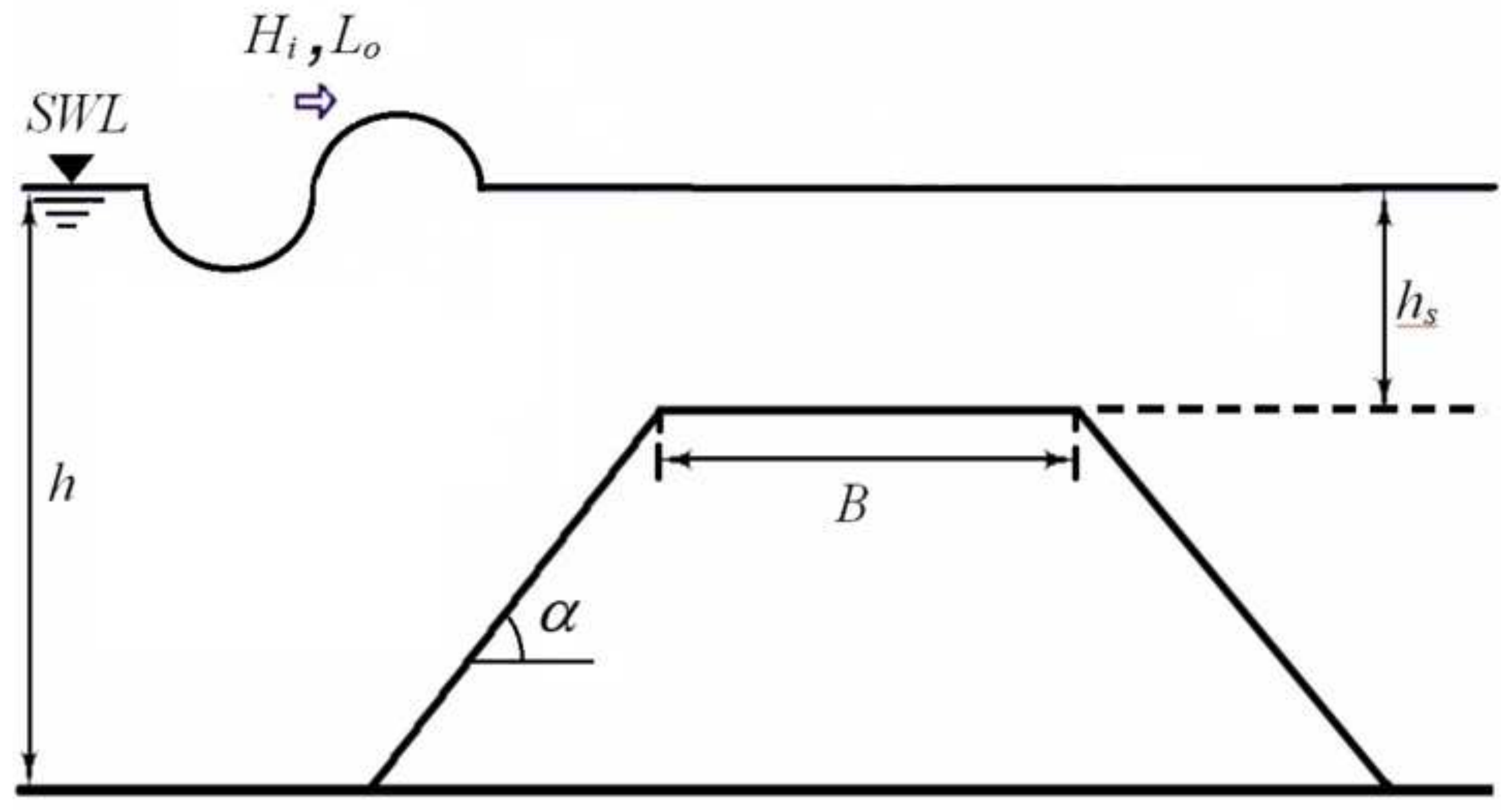




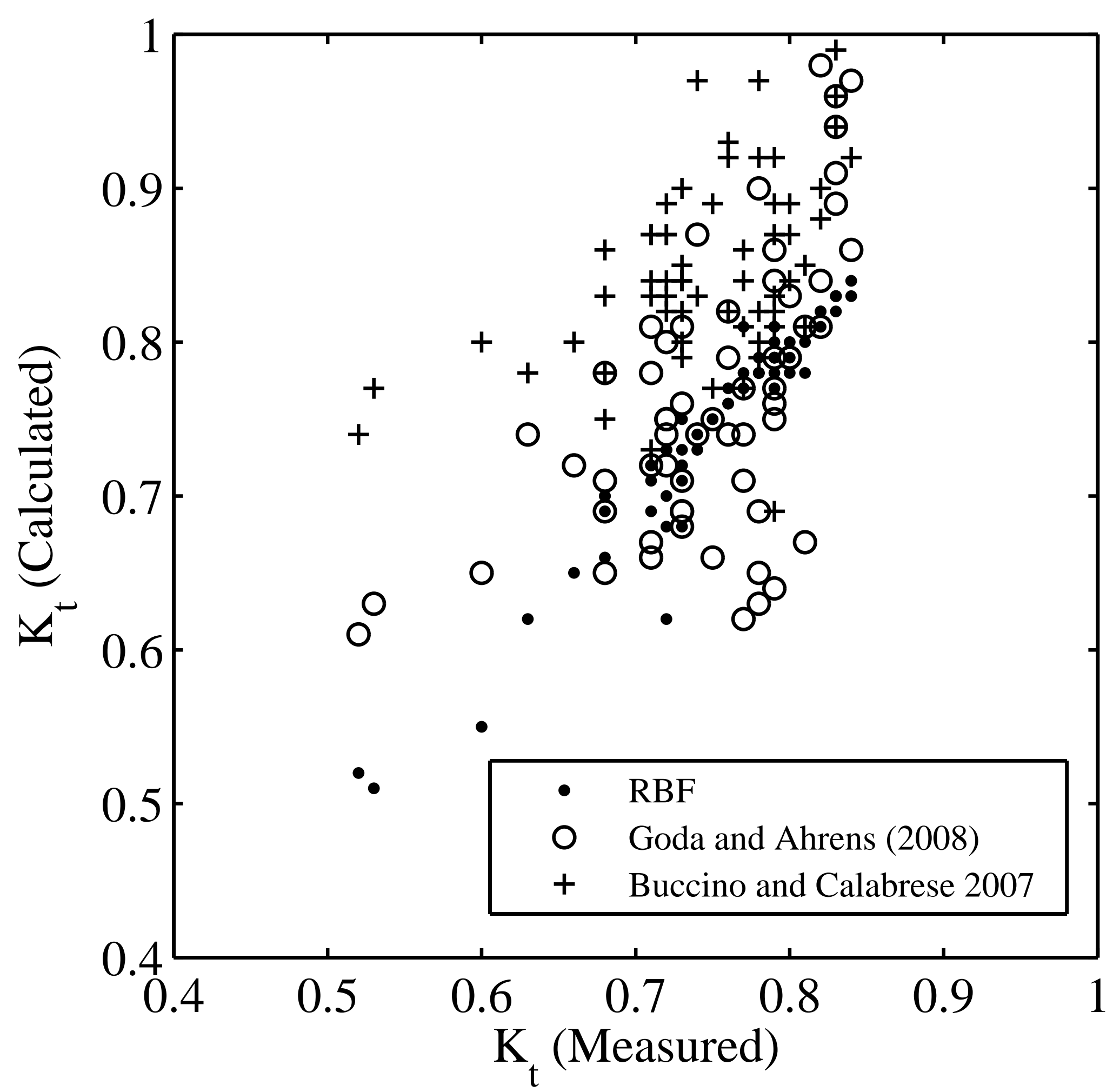




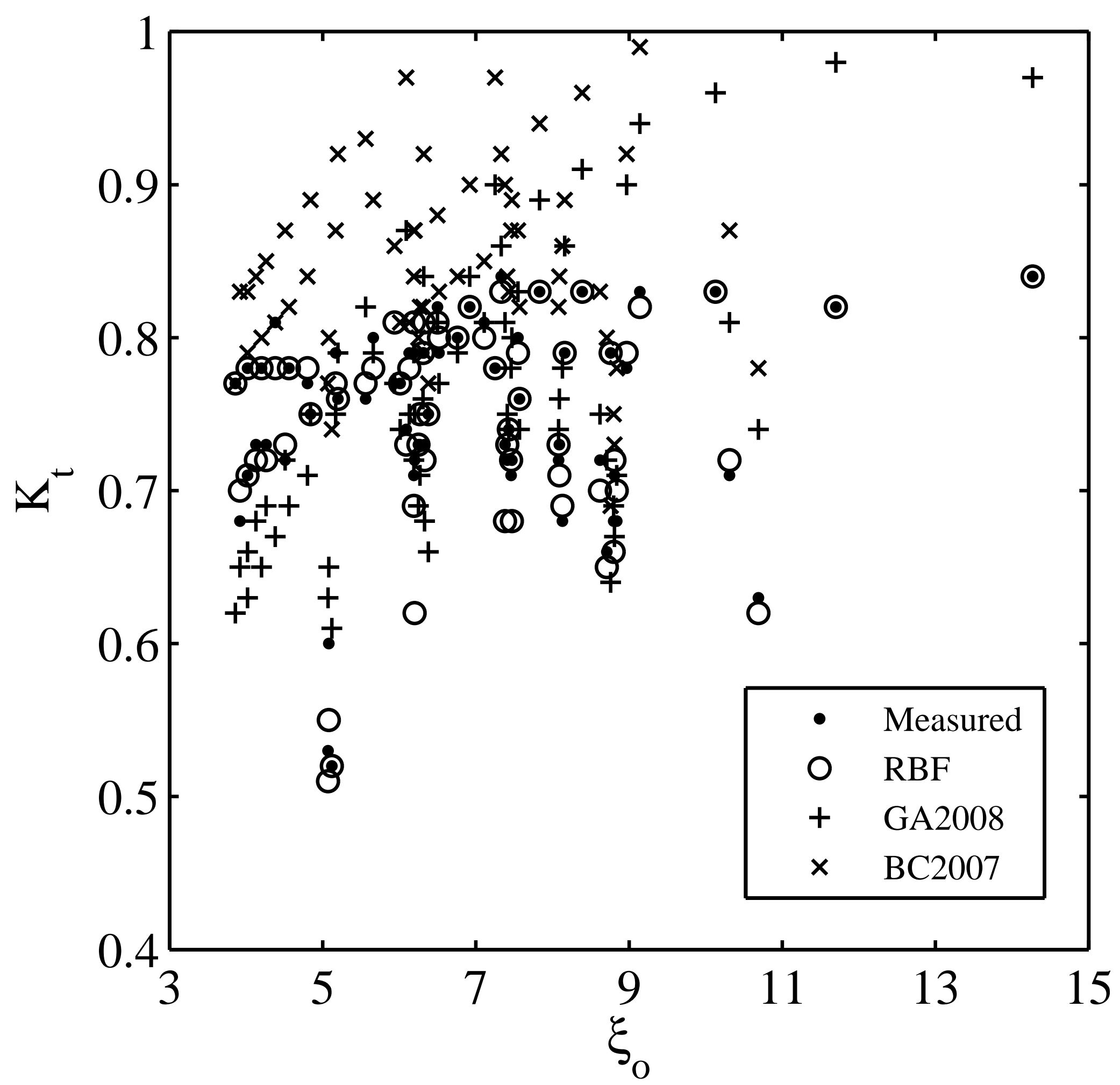




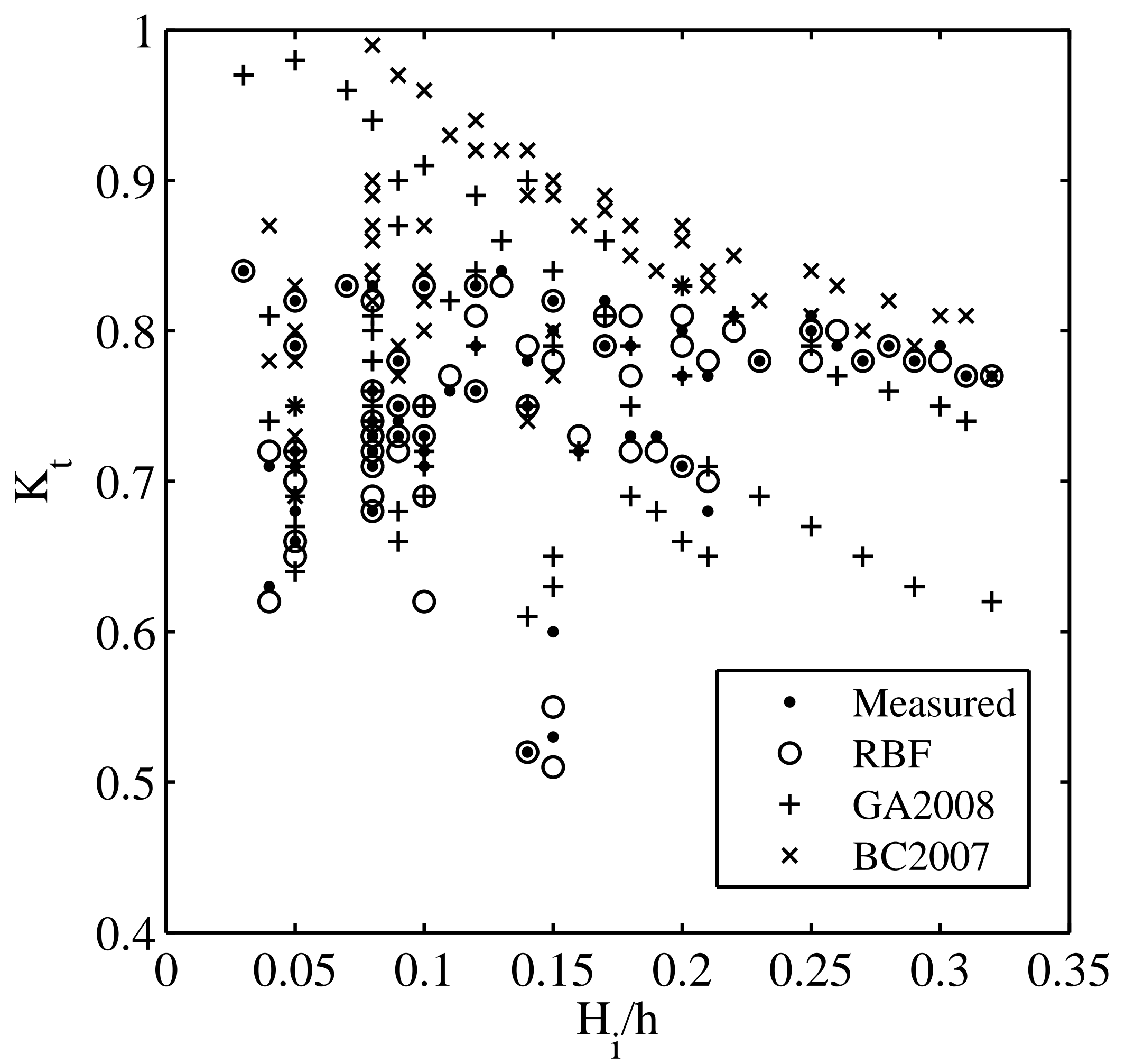




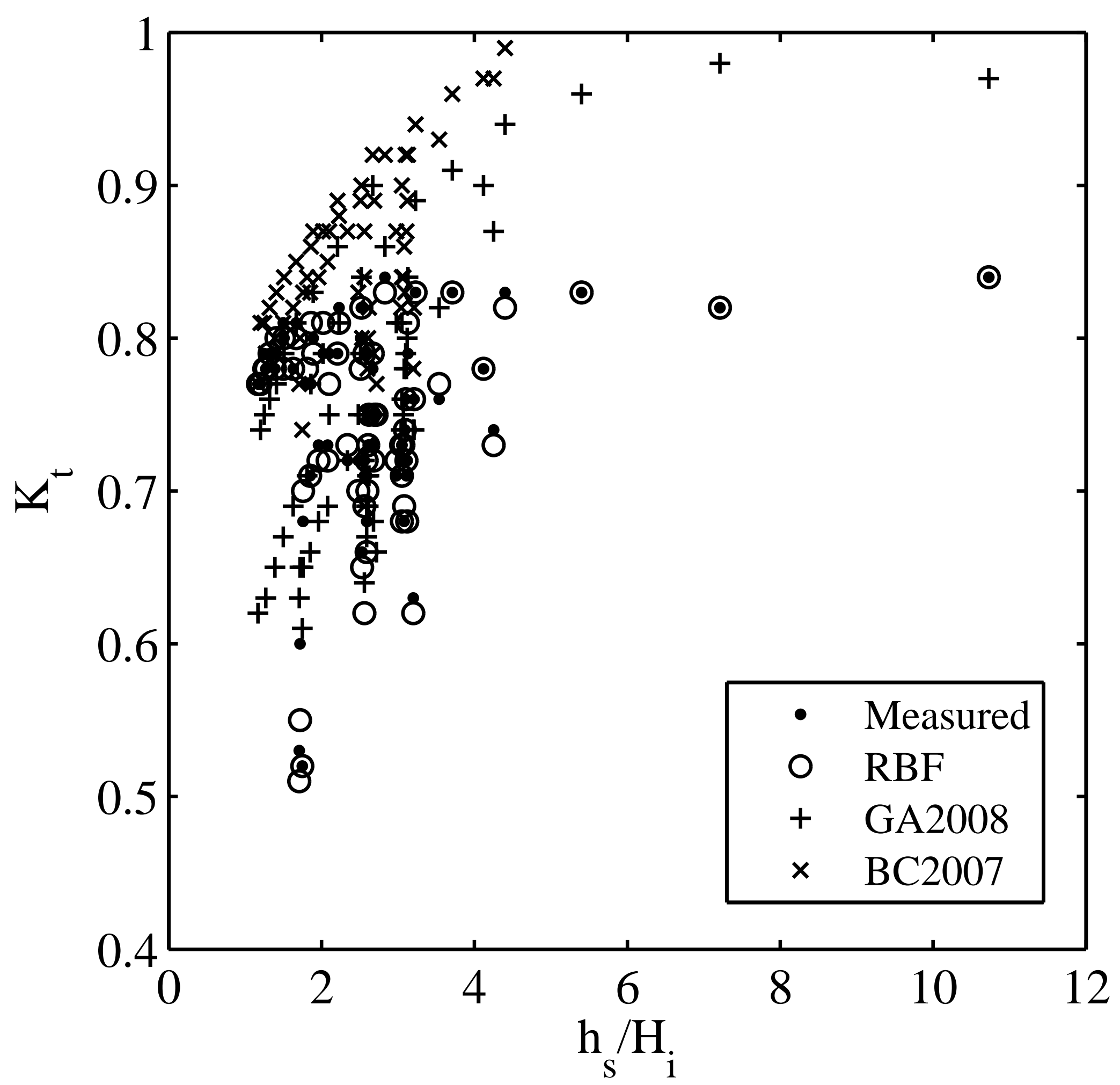




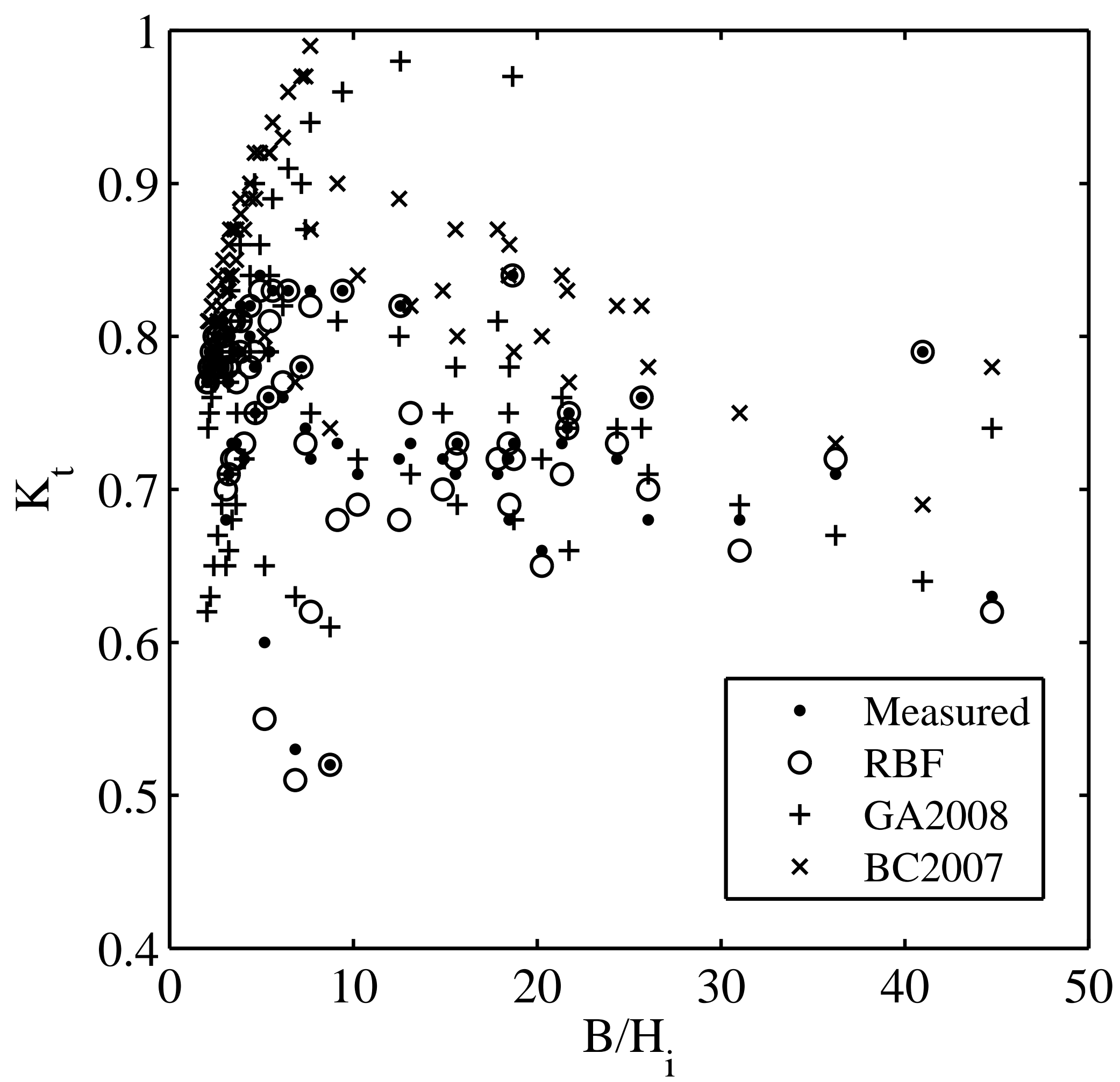




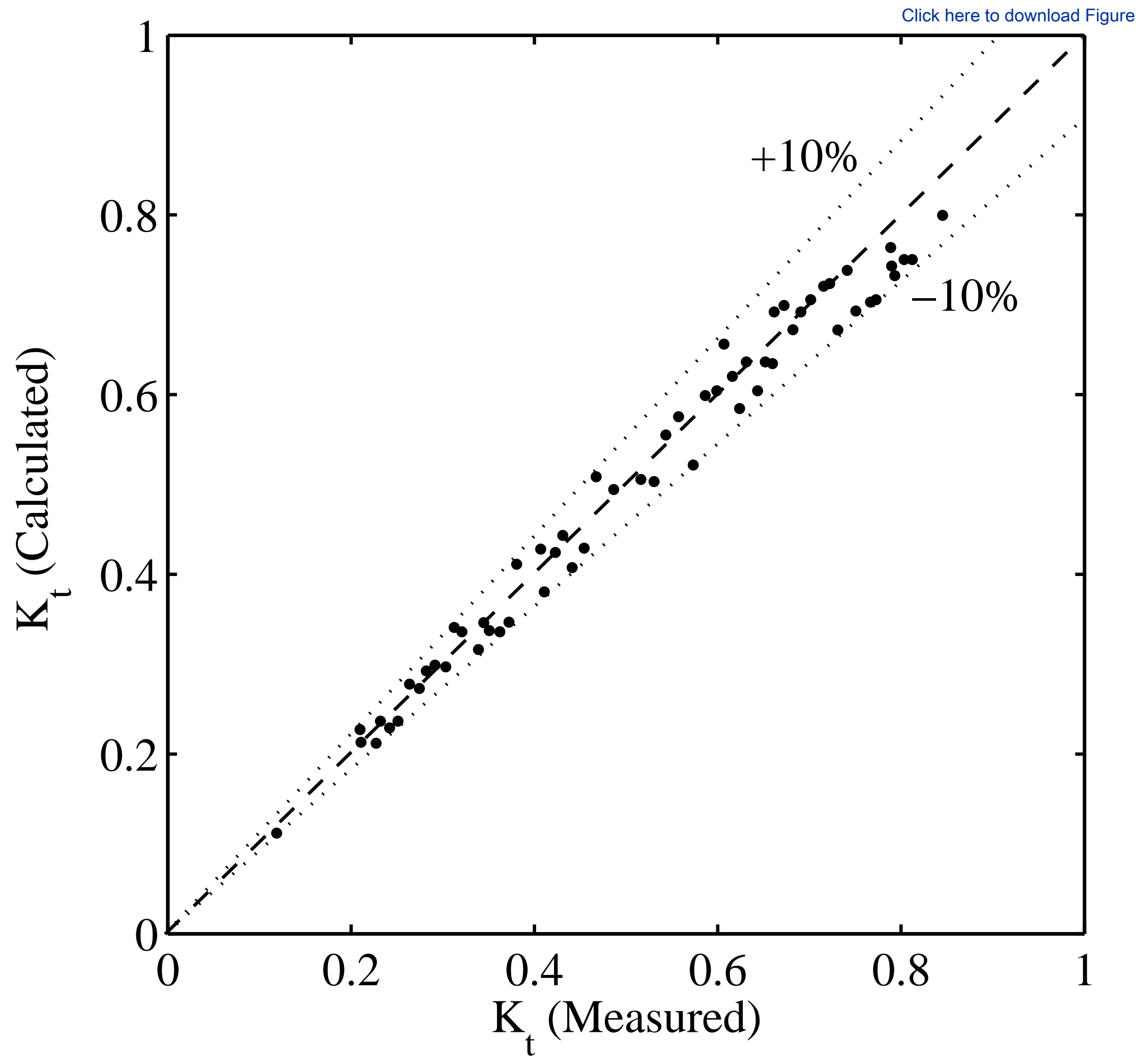




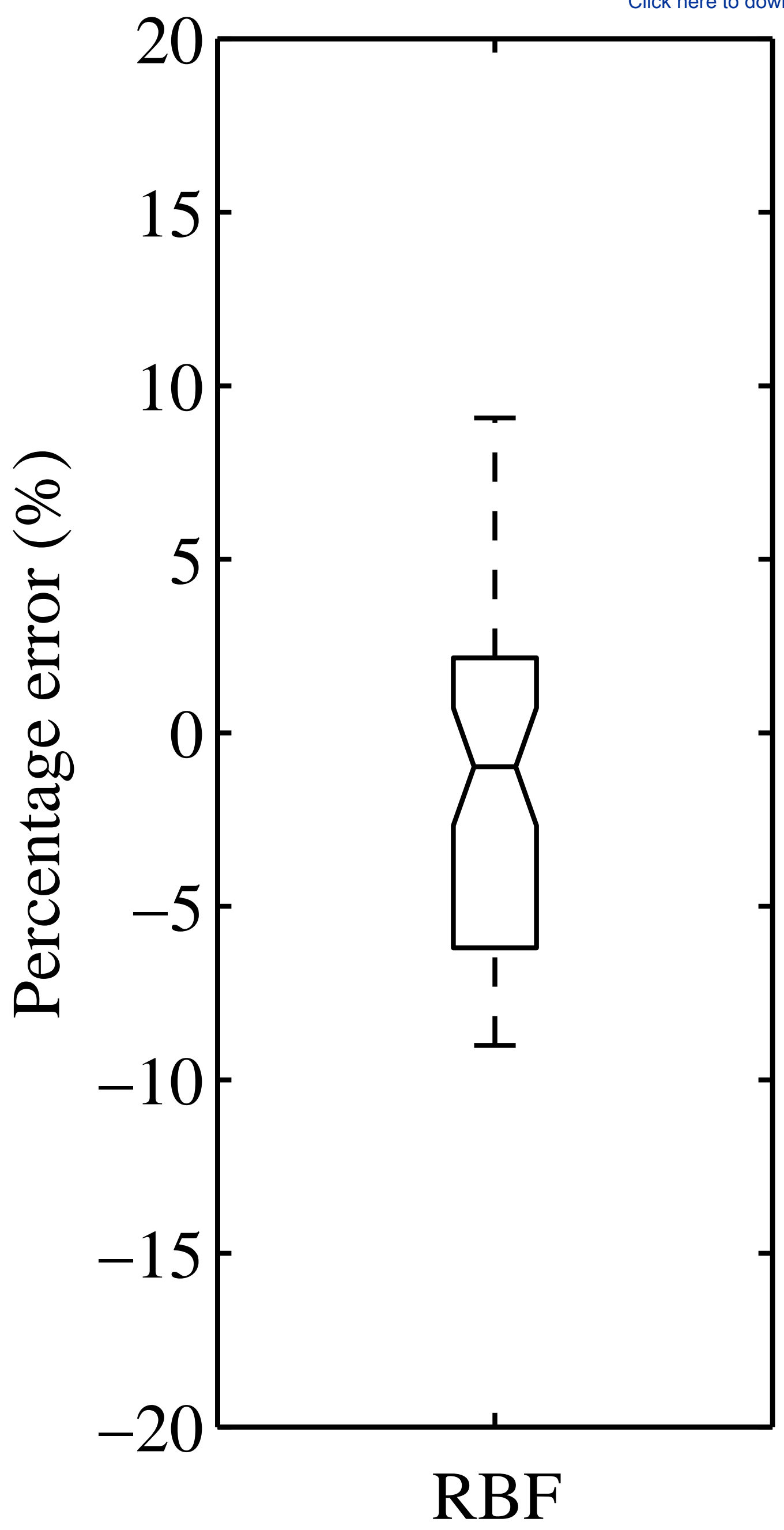




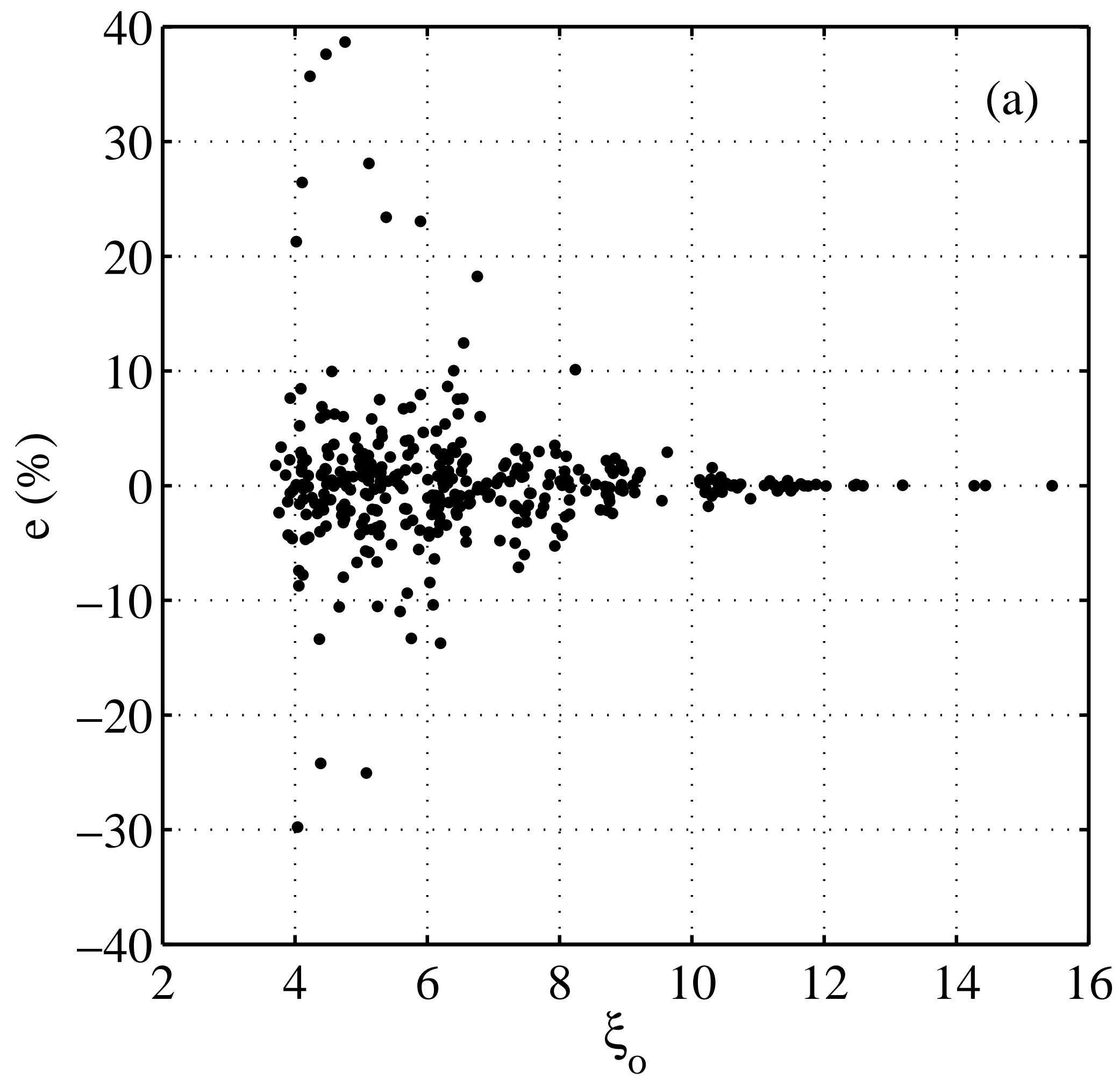


Click here to download Figure Fig6b.eps $\underline{\underline{ \pm}}$

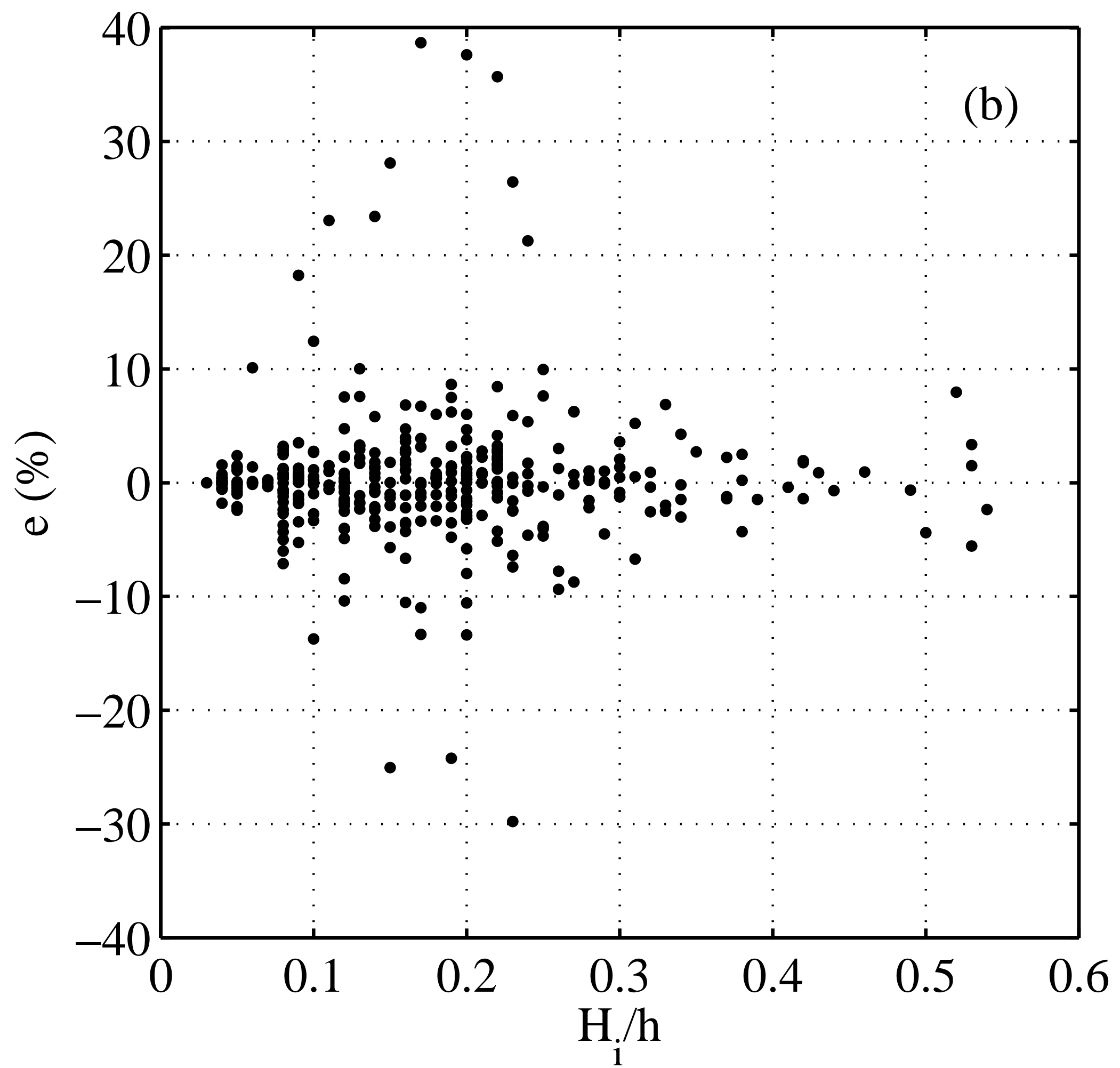


Click here to download Figure Fig6c.eps $\underline{\underline{\Perp}}$

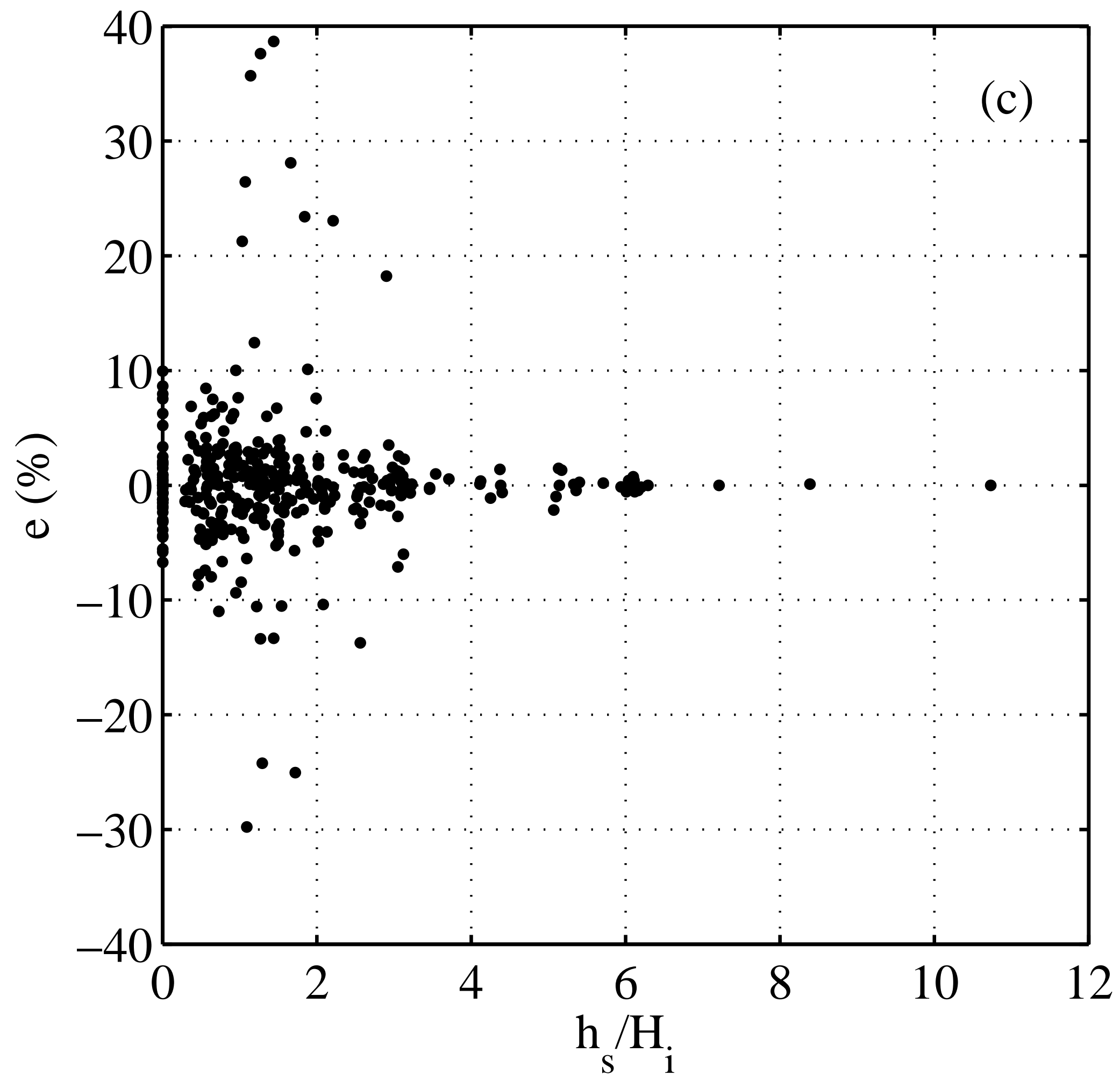




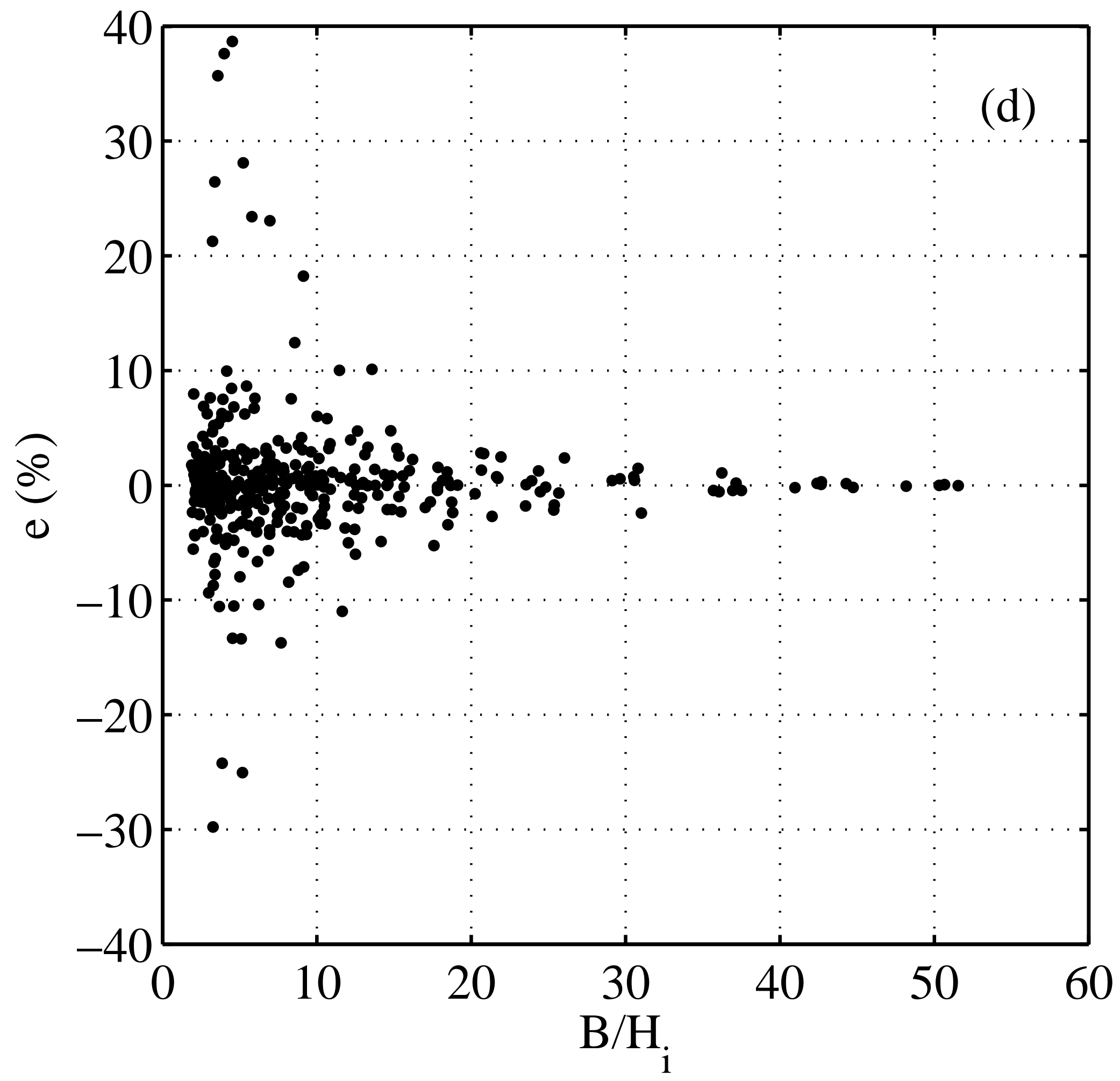


Click here to download Figure Fig7a.eps $\underline{\underline{ }}$

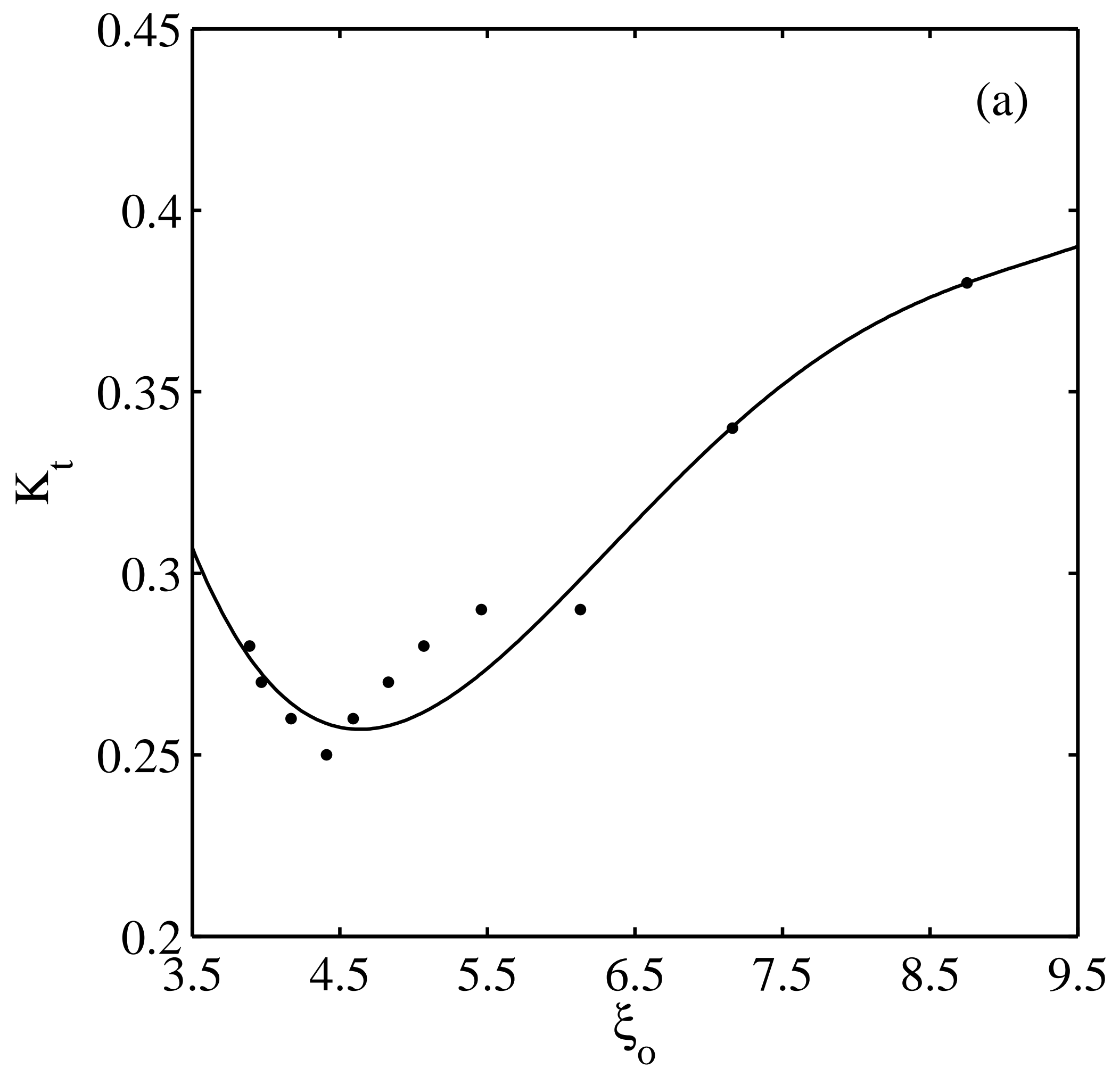


Click here to download Figure Fig7b.eps $\underline{\underline{\underline{ }}}$

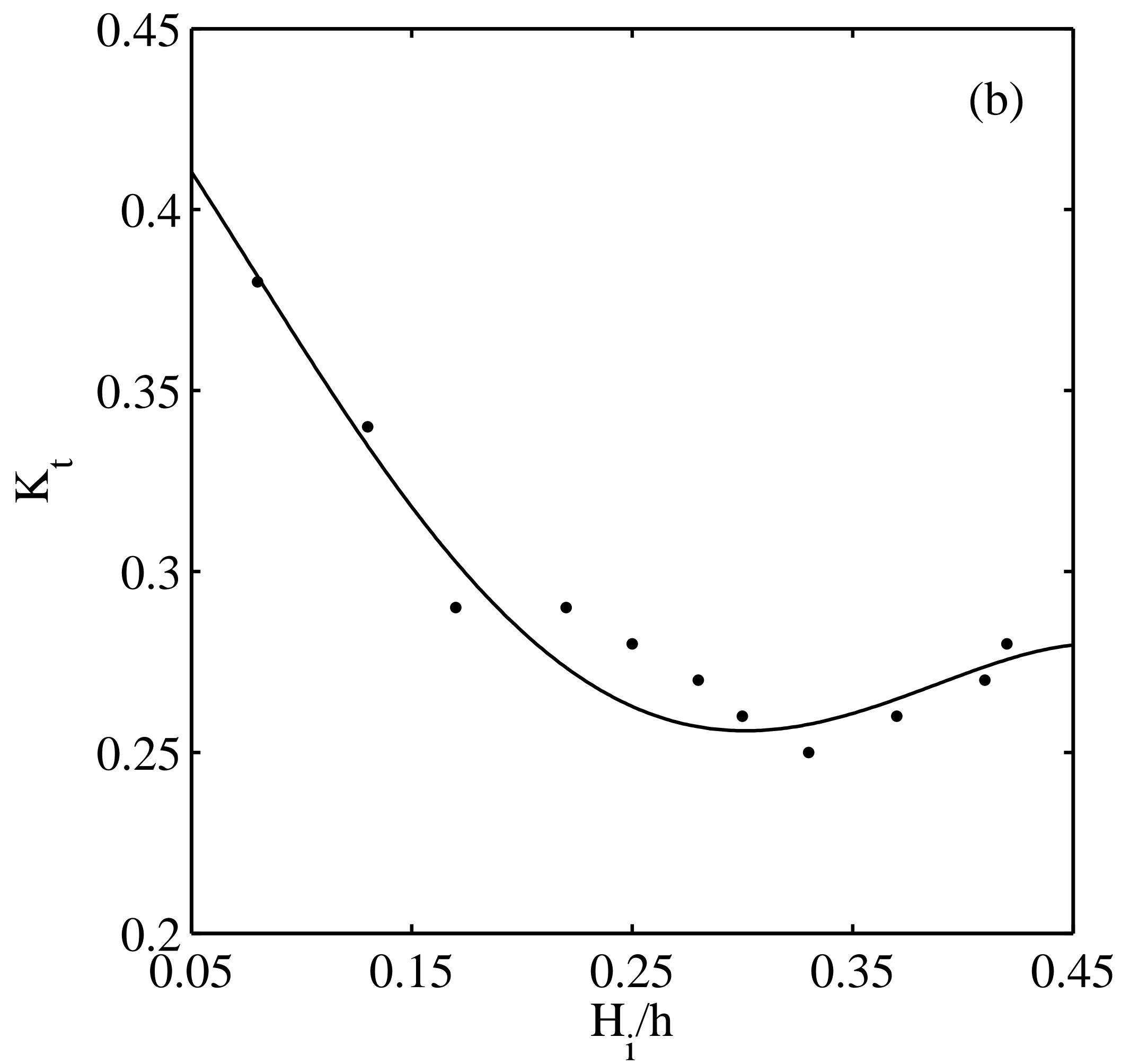




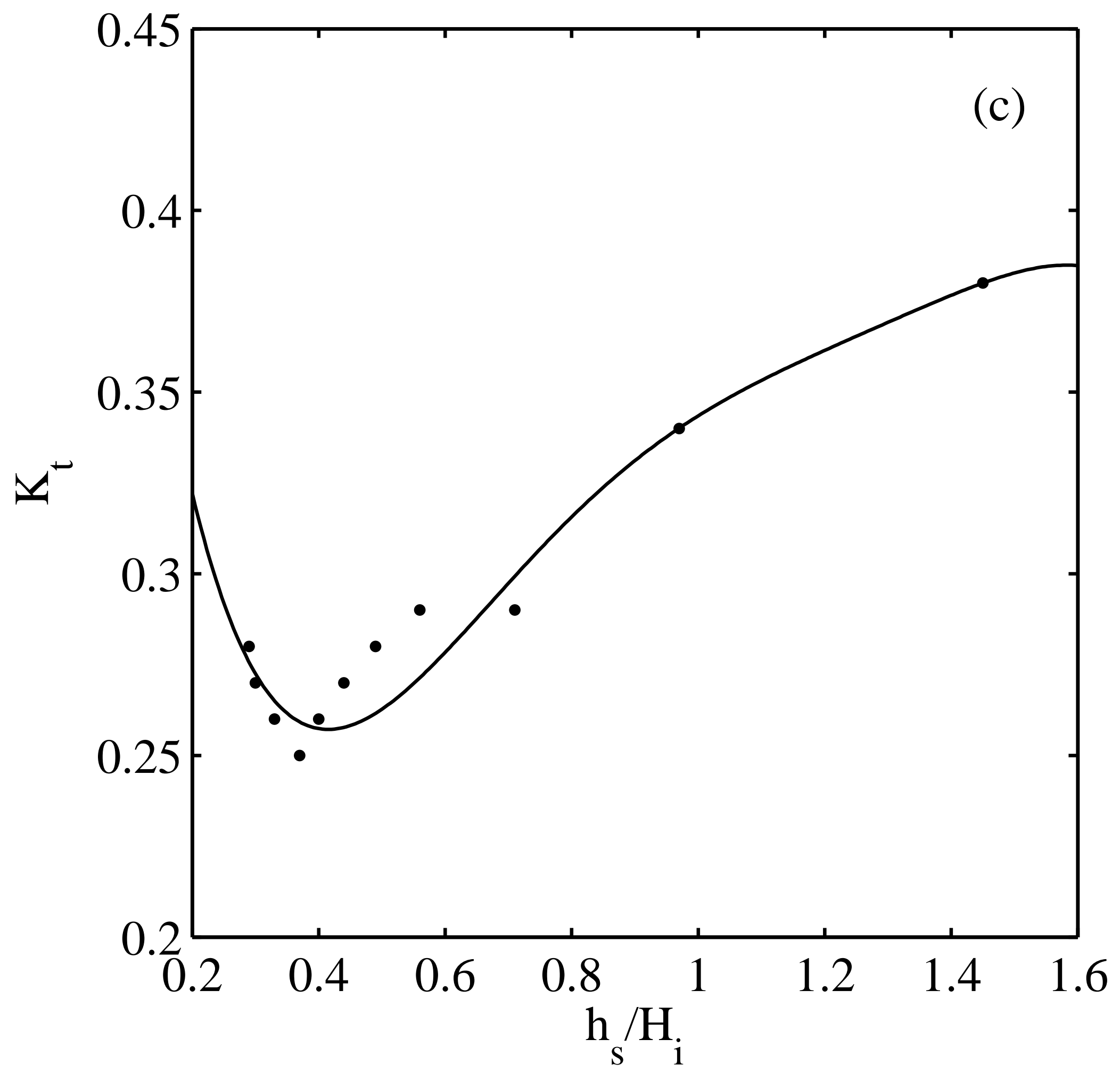


Click here to download Figure Fig7d.eps $\underline{\underline{ \pm}}$

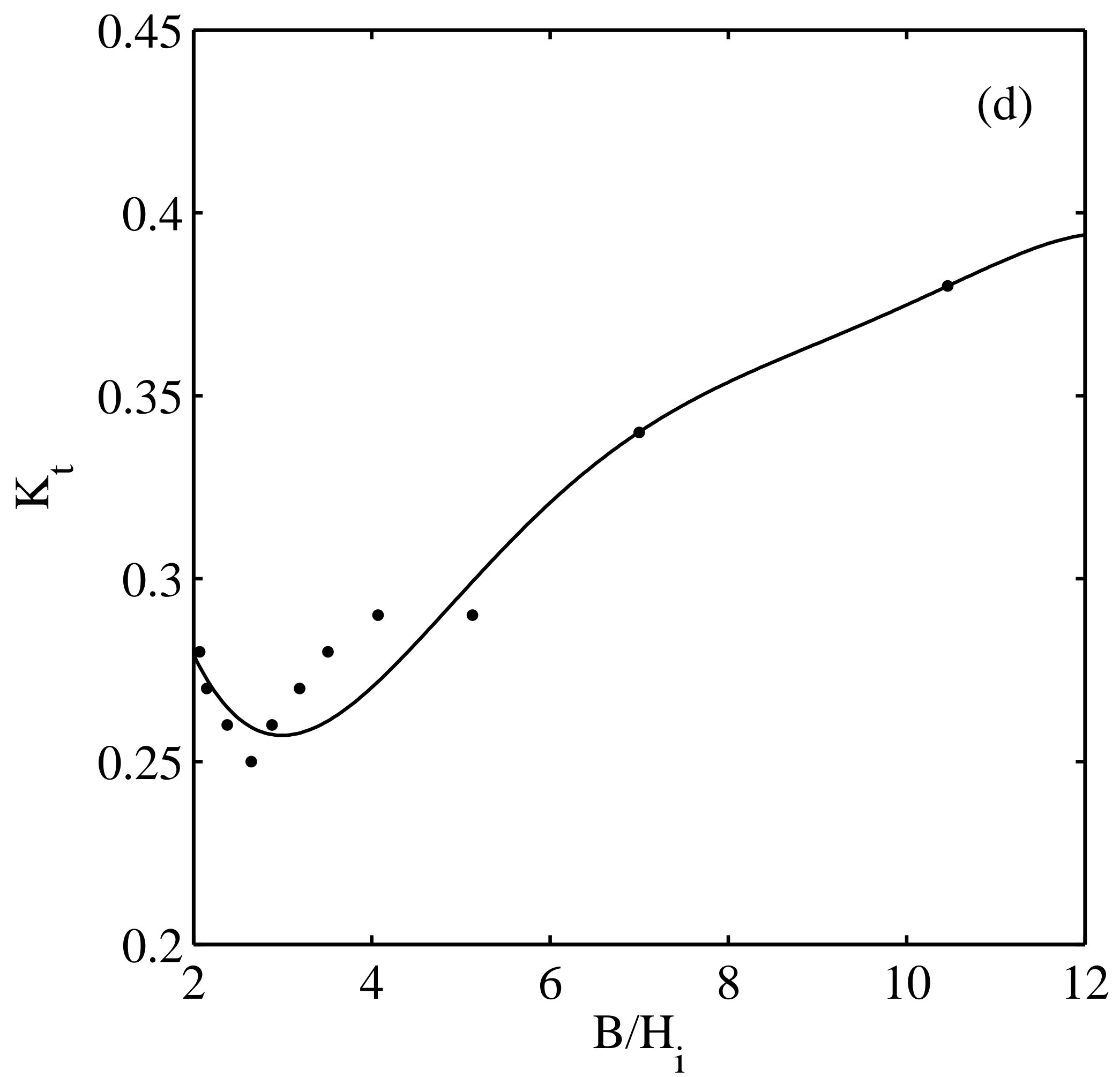


Click here to download Figure Fig8a.eps $\underline{\underline{\underline{ }}}$

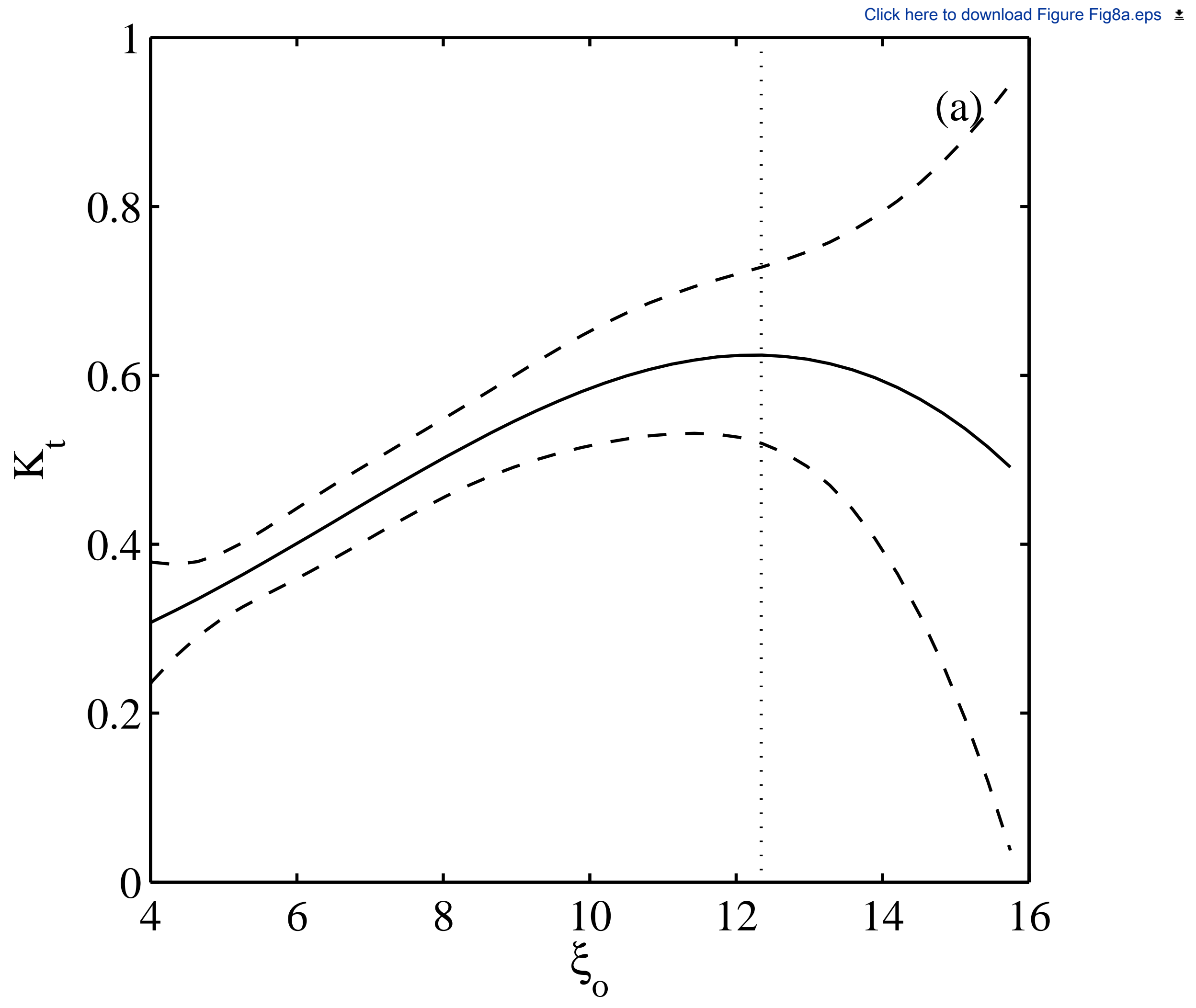




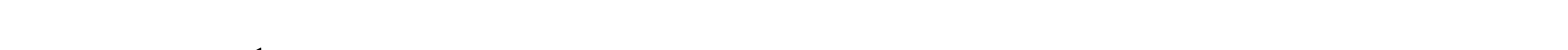

Click here to download Figure Fig8b.eps $\underline{\underline{\boldsymbol{}}}$

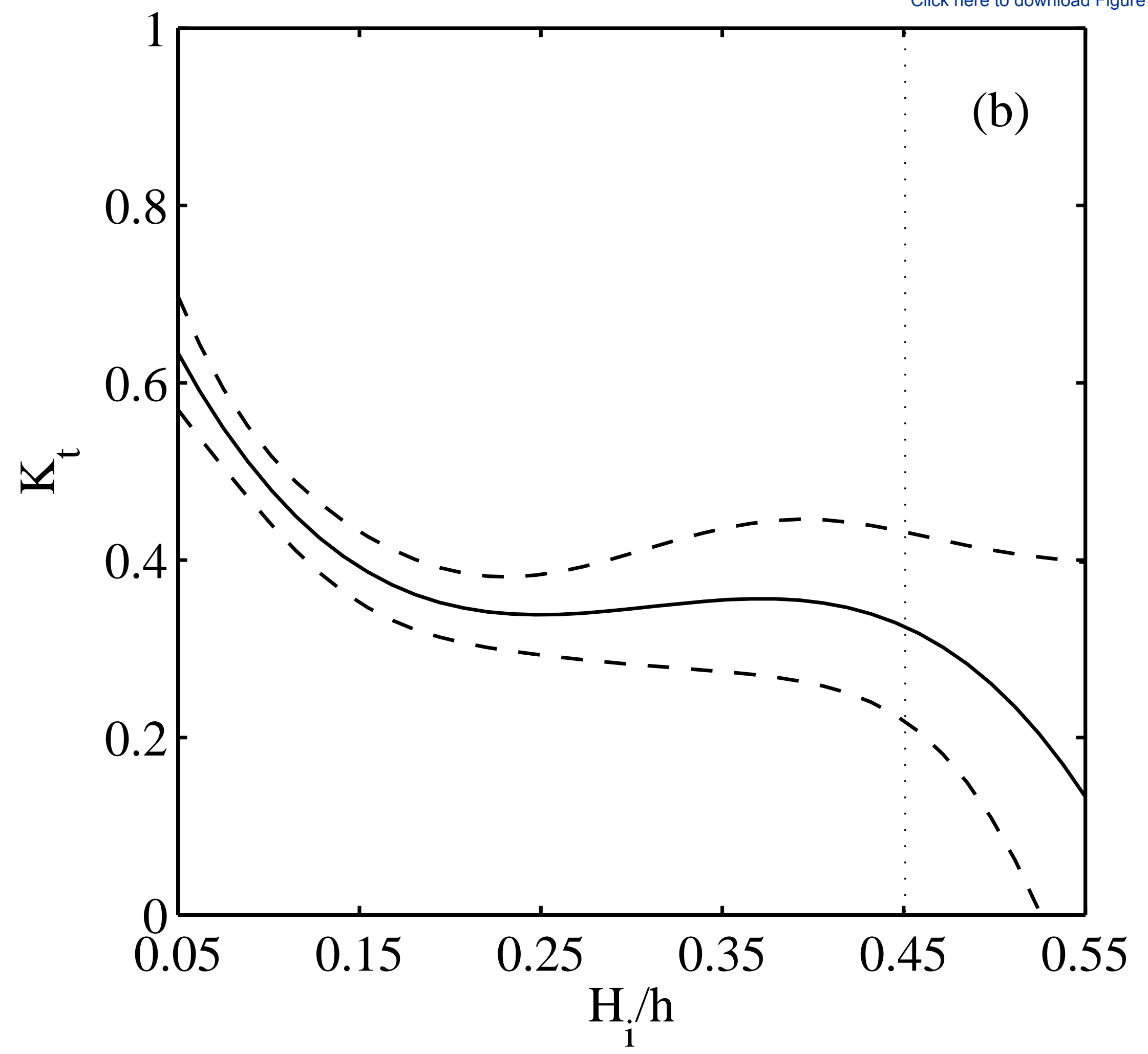


Click here to download Figure Fig8c.eps $\underline{\underline{\underline{ }}}$

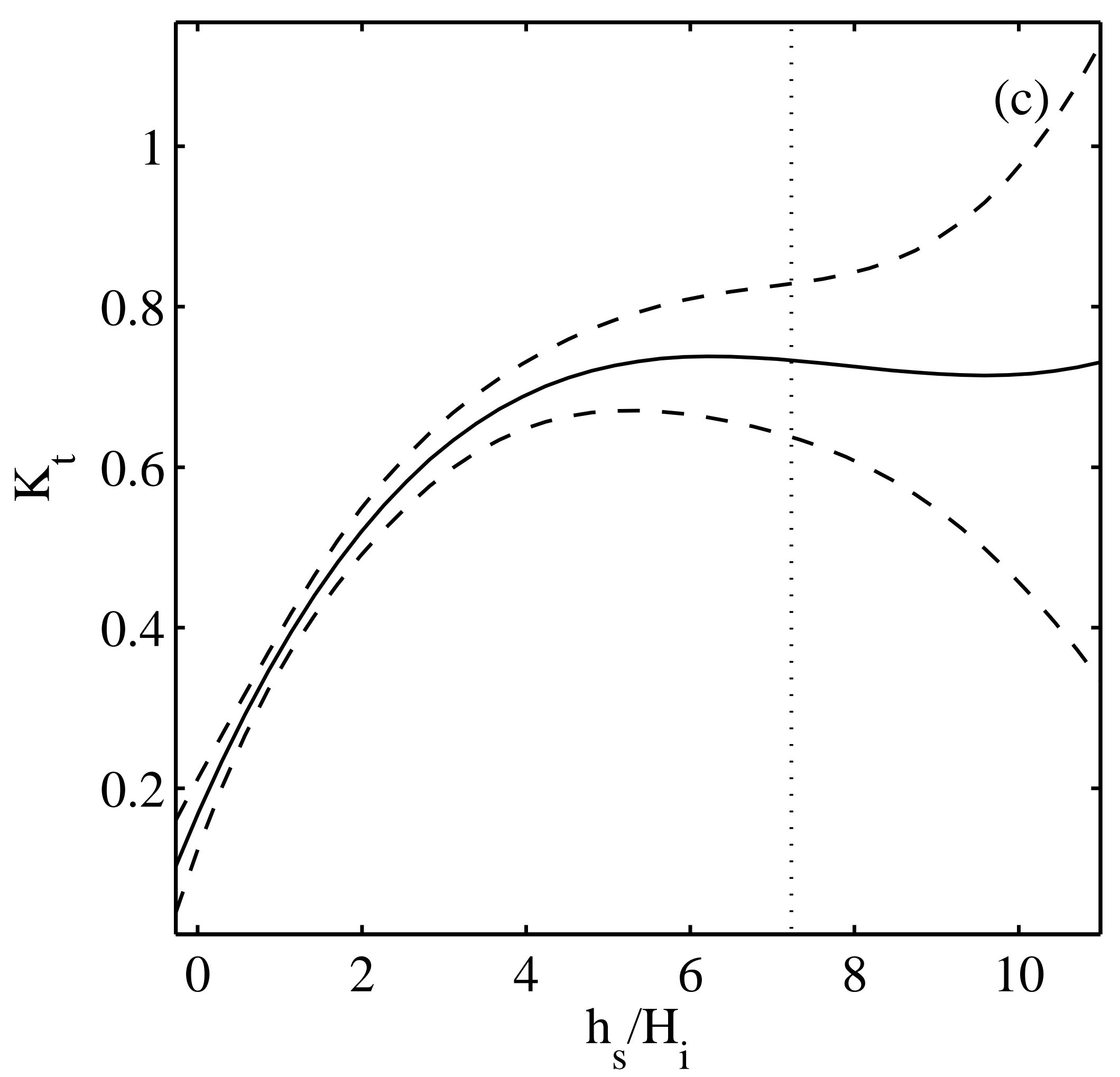


Click here to download Figure Fig8d.eps $\underline{\underline{\underline{ }}}$

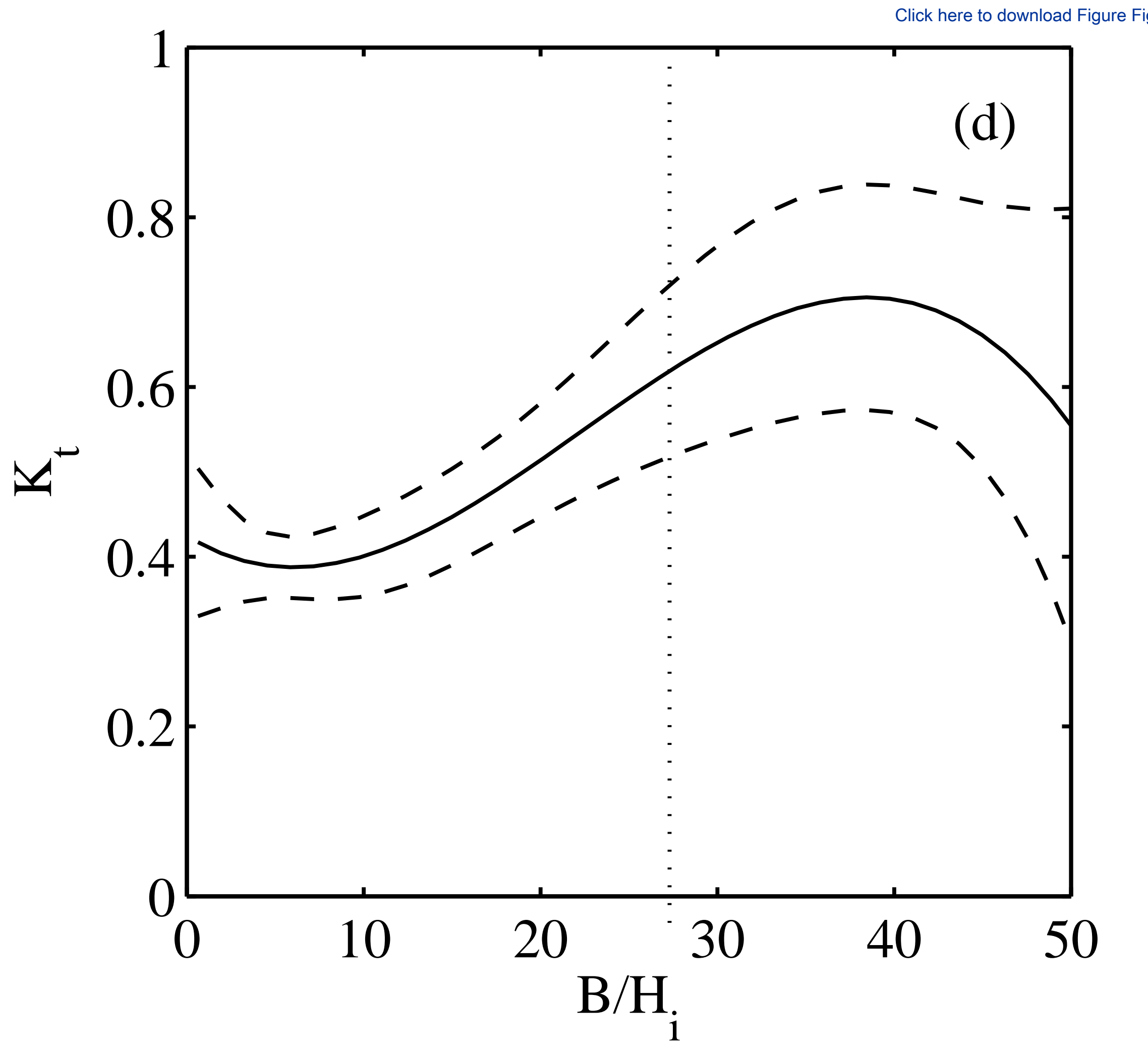

